\title{
Remote sensing of the El Hierro submarine volcanic eruption plume
}

\author{
Josep Coca $^{\mathrm{a} *}$, Thomas Ohde ${ }^{\mathrm{b}}$, Alexandre Redondo ${ }^{\mathrm{a}}$, Luís García-Weil ${ }^{\mathrm{c}}$, \\ Magdalena Santana-Casiano ${ }^{\mathrm{d}}$, Melchor González-Dávila ${ }^{\mathrm{d}}$, Javier Arístegui ${ }^{\mathrm{d}}$, Eugenio \\ Fraile Nuez, and Antonio G. Ramos ${ }^{\mathrm{a}}$ \\ ${ }^{a}$ División de Robótica y Oceanografia Computacional, IUSIANI, Universidad de Las Palmas de \\ Gran Canaria, Las Palmas de Gran Canaria, Spain; ${ }^{b}$ Leibniz Institute for Baltic Sea Research, \\ D 18119 Warnemünde, Germany; ${ }^{c}$ Departamento de Física, Universidad de Las Palmas de Gran \\ Canaria, Las Palmas de Gran Canaria, Spain; ${ }^{2}$ Instituto de Oceanografia y Cambio Global, \\ IOCAG, Universidad de Las Palmas de Gran Canaria, Las Palmas de Gran Canaria, Spain; \\ ${ }^{e}$ Instituto Español de Oceanografia-Centro Oceanográfico de Canarias (IEO-COC), Santa Cruz \\ de Tenerife, Spain
}

(Received 17 September 2013; accepted 9 June 2014)

Submarine volcanic eruptions took place at the island El Hierro (Canary Islands) between October 2011 and March 2012. The event produced plumes of discoloured waters due to the discharge of volcanic matter, magmatic gases, and hydrothermal fluids. The expelled materials, which behaved like oceanic tracers, were detected from the site of the volcano to the open sea by remote-sensing techniques using different level-2 (L2) products of the Moderate Resolution Imaging Spectroradiometer (MODIS) sensor. In order to assess the effect of the anomalous turbidity, three atmospheric correction schemes were evaluated: SeaWiFS Data Analysis System (SeaDAS) standard, near-infrared-shortwave-infrared (NIR-SWIR), and Management Unit of the North Sea Mathematical Models (MUMM). The comparison between them verified that the SeaDAS standard atmospheric correction was the most suitable. The downwelling diffuse attenuation coefficient at $490 \mathrm{~nm}$ $\left(K_{\mathrm{d}}(490)\right)$ was used as a measure of plume intensity in comparison with other submarine volcanic eruptions. The MODIS-derived $K_{\mathrm{d}}(490)$ values verified that the intensity of the El Hierro plume was moderate. Only in some specific situations did the values barely exceed $0.4 \mathrm{~m}^{-1}$. The remote-sensing reflectance $\left(R_{\mathrm{rs}}\right)$ was used for the characterization of the affected waters. The $R_{\mathrm{rs}}$ spectra also allowed a comparison with other volcanic and sulphide events reported in previous studies. Similarities were found, both with submarine volcanic eruptions in the southwestern Pacific and with sulphide events at the Namibian coast, in composition and properties of optically active water constituents. A classification schema based on $K_{\mathrm{d}}(490)$ values and $R_{\mathrm{rs}}$ ratios was developed and used in connection with MODIS red-green-blue (RGB) composites as well as surface current velocities from altimeter missions to investigate the spatio-temporal development of the volcanic plume. The spreading and transport of volcanic material observed at the ocean surface was caused by the predominant surface currents coupled with different mesoscale eddies. Discoloured waters were identified more than $200 \mathrm{~km}$ away from the eruption site. Field data from oceanographic surveys verified the high concentration of sulphur compounds in affected waters and confirmed the overestimation by the MODIS default algorithm of chlorophyll- $a$ concentrations in the volcanic plume.

\section{Introduction}

The Canary Islands are a volcanic archipelago located in the Atlantic Ocean near to the Northwest African coast. Historical records from the twentieth century to the present

*Corresponding author. Email: jcoca@pesca.gi.ulpgc.es 
situate all volcanic eruptions in the western part of the Canary archipelago. The first eruption took place at Tenerife (1909), the next two events occurred at La Palma (1949 and 1971), and the most recent episode took place in October 2011, at El Hierro, the youngest of the Canary Islands (Macau-Vilar 1963). This last eruption was not sub-aerial as the previous ones, and it occurred in the ocean $1.8 \mathrm{~km}$ from the coastal town of La Restinga located at the southernmost part of El Hierro (Figure 1). Even though it is estimated that $75 \%$ of the total yearly magma release comes from submarine eruptions (Resing et al. 2011), they are less reported than sub-aerial ones, due to both their minor impact in daily human life and because most of these underwater eruptions are difficult to detect because they occur at great depths at the bottom of the oceans. Observational conditions are improved when the eruption takes places in shallow waters. In these cases, the presence of discoloured waters is frequently observed, and, on occasion, volcanic fragments floating at the surface (Urai and Machida 2005; Mantas, Pereira, and Morais 2011; Shi and Wang 2011; Fraile-Nuez et al. 2012; Santana-Casiano et al. 2013).

These submarine eruptions usually have a greater significance when they take place next to a populated area. During the El Hierro eruption, the population of the nearby village La Restinga was evacuated. The local marine wildlife and marine reserve were seriously affected because submarine volcanic eruptions release toxic substances that impact the marine natural ecosystem (Carracedo et al. 2012) and may also act as fertilizers of phytoplankton (Mantas, Pereira, and Morais 2011; Santana-Casiano et al. 2013).

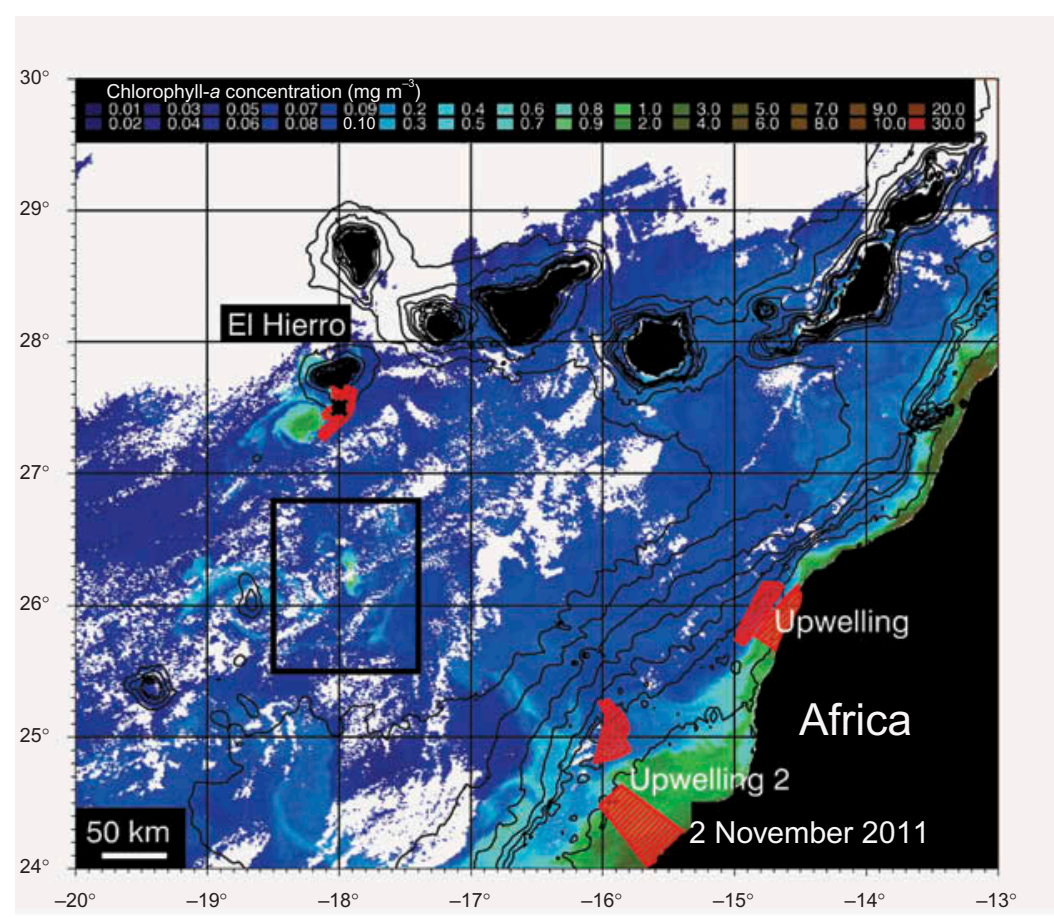

Figure 1. Chl- $a$ image from MODIS-AQUA on 2 November 2011, showing the study area, the location of the El Hierro volcanic eruption, and the areas (red shapes) used for STD, NIR-SWIR, and MUMM atmospheric correction adjustment and/or comparison. The black box indicates the area where material from the eruption and the upwelling converge. 
Subsequently, economic activities such as tourism, mainly related to scuba diving and fishing, were also affected.

The first patches of pale-coloured water related to the eruption were observed $1.8 \mathrm{~km}$ south of El Hierro on 10 October 2011 (IGN, Instituto Geografico Nacional, www.ign.es). The structure of the volcano experienced significant growth, rising to $89 \mathrm{~m}$ below the sea surface from an initial depth of $363 \mathrm{~m}$ (Rivera et al. 2013). Ash and emitted gases from the volcano induced drastic changes in physical and chemical properties in the waters south of El Hierro. These effects comprised thermal changes; water acidification; deoxygenation, with oxygen depletion nearing anoxic levels; enhanced light attenuation; discolouration; negative redox potential; $\mathrm{pH}$ decrease (from 8 to nearly 5); maximum concentrations of reduced sulphur and total Fe(II) species $\left(200\right.$ and $50 \mu \mathrm{mol} \mathrm{kg}{ }^{-1}$, respectively); and higher concentrations of dissolved copper, cadmium, lead, and aluminium with maximum values of 6.1, 6.7, 5.8, and 2.122 nanomoles, respectively (FraileNuez et al. 2012). In the surrounding area, temperature anomalies were registered of up to $20^{\circ} \mathrm{C}$, and the concentration of dissolved gases $\left(\mathrm{CO}_{2}\right.$ and $\left.\mathrm{SO}_{2}\right)$ increased several hundred times (Fraile-Nuez et al. 2012). The depletion of oxygen was caused by oxidation of reduced gas species such as sulphur and Fe(II) emitted by the volcano (Santana-Casiano et al. 2013). A discolouration of the surface water was observed ranging from light-green to milky blue, and to a dark brown. Surface waters with dark shades of colour near the volcano were due to iron sulphurs, and these evolved to light green shades with a great range of tints caused by the oxidation of copper sulphides. The oxidation of hydrogen sulphide to elemental sulphur made the water milky (Weeks et al. 2004).

The presence of the above-mentioned features from submarine eruptions in shallow waters allows us to study and trace them using remote-sensing observations of the ocean surface (Urai and Machida 2005; Mantas, Pereira, and Morais 2011; Shi and Wang 2011). Rafts and plumes discolour surrounding waters depending on their composition (Urai and Machida 2005) and on their characteristics (lava flows, bubbles of lava, ashes, volcanic plumes and pumice) (Siebert and Simkin 2002). Urai and Machida (2005) used ASTER reflectance products to discriminate two kinds of discoloured water produced by a submarine eruption at Satsuma-Iwojima (Japan). Mantas, Pereira, and Morais (2011) showed that the Moderate Resolution Imaging Spectroradiometer (MODIS)-derived $R_{\mathrm{rs}}$ spectra can be used to characterize several types of discoloured water plumes of volcanic origin in Tonga (Southwest Pacific Ocean). Shi and Wang (2011) compared the spectra during an eruption in the Pacific Ocean with those corresponding to previous dates. These authors also performed a comparison of the $R_{\mathrm{rs}}$ spectra of volcanic plumes with other water types (clear, productive, sediment suspended, river plume).

Once in the marine environment, the volcanic material can be transported and dispersed far from the point from where it was expelled. Bryan et al. (2004) showed that pumice clasts produced in a shallow-marine eruption in Tonga formed pumice rafts. These were driven by winds, waves, and currents reaching the eastern coast of Australia a year later, more than $3000 \mathrm{~km}$ from the focal point of the eruption. The surface velocity currents were obtained combining wind data with geostrophic currents derived from seasurface height coming from altimeter data. Floating rocks were also observed several times at the El Hierro eruption, but they remained buoyant for a short time (www.ign.es). The suspended volcanic material introduced into the water column was transported away by ocean currents during the El Hierro episode. Adams et al. (2011) found that mesoscale eddies, revealed from the analysis of altimeter observed sea level anomalies (SLAs), provide a suitable mechanism for transporting material from deep hydrothermal vents hundreds of kilometres from its source. The Canary region is known for its high 
mesoscale activity compared to other eastern boundary regions (Pingree and Garcia-Soto 2004). The source of this high variability is the flow perturbation produced by the islands, given rise to a zonal band of long-lived eddies known as the Canary Eddy Corridor (Sangrà et al. 2009). Analysis of ocean spectral reflectance data detected by ocean colour remote sensors (Urai and Machida 2005; Mantas, Pereira, and Morais 2011) can be used to describe the spatial and temporal evolution of these volcanic discoloured waters.

The objective of this work is to characterize the spatio-temporal evolution of waters containing material expelled by the El Hierro volcanic eruption using remote-sensing data supported by oceanographic field samples of chlorophyll- $a$ (chl- $a$ ) and sulphur-reduced species. The spectral information recorded by remote sensors working in the visible and near-infrared (NIR) regions of the electromagnetic spectrum together with geostrophic velocities derived from radar altimeters as well as the sea surface temperature (SST) is used to analyse the physical factors involved in the evolution of the volcanic plume.

The MODIS algorithm for the determination of chl- $a$ concentration is analysed for the application in waters influenced by El Hierro volcanic eruption. Another aim is the verification of the suitability of different algorithms of atmospheric correction. Spectra of remote-sensing reflectance are used for the characterization of different kinds of waters present in the study area and for the comparison with volcanic events in the southwestern Pacific Ocean as well as with sulphide events at the Namibian coast. In the article, a classification scheme is developed with the purpose of the identification of waters influenced by volcanic activity and is used to follow their spreading and evolution.

\section{Methodology}

\section{Satellite data}

Level-1A (L1A) diurnal granules of MODIS on board the AQUA satellite, covering the study area of $24^{\circ}$ to $30^{\circ} \mathrm{N}$ and $20^{\circ}$ to $13^{\circ} \mathrm{W}$ (Figure 1) from October 2011 to February 2012, were downloaded from the Ocean Color Web (http://oceancolor.gsfc.nasa.gov/).

MODIS granules were processed from L1A to L2 using SeaWiFS Data Analysis System (SeaDAS) 6.4 (http://SeaDAS.gsfc.nasa.gov/). L2 products such as the normalized water-leaving radiance $\left(L_{\mathrm{nw}}\right), R_{\mathrm{rs}}$, turbidity index (see Wang and Shi 2007), $K_{\mathrm{d}}(490)$ (the diffuse attenuation coefficient at the wavelength of $490 \mathrm{~nm}$ is used as a measure of the turbidity of water), chl- $a$, SST, $b_{\mathrm{b}}$ (total backscattering coefficient, which accounts for water turbidity at several wavelengths), and the parameters required for the Management Unit of the North Sea Mathematical Models (MUMM) (see Ruddick, Ovidio, and Rijkeboer 2000) adjustment were selected (SeaDAS nomenclature). L2 products were mosaicked using the SeaDAS 'mapimg' function and then exported to binary data format. ENVI images $\left(0.01^{\circ}\right.$ of spatial resolution) were generated from the binary data (http:// www.exelisvis.com).

SST from individual satellite passes, daytime, and night-time SST from thermal infrared bands of the sensors MODIS-AQUA and MODIS-TERRA were binned using SeaDAS to produce 5-day moving averages. These syntheses produced cloud-free images that allowed for monitoring mesoscale structures present in the study area.

SLA data from all available altimeter missions were used in order to achieve the best possible sampling of the study area. The operational instruments for the period of interest from October 2011 to March 2012 were the altimeters aboard Jason 1, Jason 2, and Envisat. The SLA data were obtained from the Archiving, Validation and Interpretation of Satellite Oceanography data project (AVISO). They were interpolated and resampled onto 
a grid of $0.25^{\circ}$ resolution as well as averaged over a 7-day interval period (SSALTO/ DUACS User Handbook 2013). From these SLA data, surface current velocities were computed using geostrophy (Chelton, Schlax, and Samelson 2011).

\section{Atmospheric correction}

Owing to the fact that unusual turbidity is caused by volcanic material, alternative atmospheric corrections besides the SeaDAS standard atmospheric corrections were tested. The following three atmospheric corrections implemented in SeaDAS were compared: SeaDAS standard (STD) (see Stumpf et al. 2003 and Bailey, Franz, and Werdell 2010), near-infrared-shortwave-infrared (NIR-SWIR) (Wang and Shi 2007), and MUMM (Ruddick, Ovidio, and Rijkeboer 2000).

The SeaDAS standard atmospheric correction uses an optical model to overcome the black pixel assumption at NIR wavelengths and retrieve the water-leaving reflectance at these wavelengths. This method was implemented by the National Aeronautics and Spatial Administration (NASA) Ocean Biology Processing Group (Bailey, Franz, and Werdell 2010).

Wang and Shi (2007) developed the NIR-SWIR approach, which uses the SWIR and NIR wavelength range for atmospheric correction of MODIS data. This correction switches between standard NIR correction (open waters) and SWIR correction (turbid and/or productive waters). Even though the use of SWIR bands increases the noise, due to their lower signal to noise ratio (Wang and Shi 2007), these authors found that it improves the retrieval over turbid waters while standard NIR processing performs better over open waters. The switch used the value of the turbidity index developed by Wang and Shi (2007). This index, which is based on the Rayleigh corrected top-of-atmosphere reflectance ratio between $748 \mathrm{~nm}$ and $1240 \mathrm{~nm}$, is operated prior to the atmospheric correction. Wang and Shi (2007) fixed the switch at values of the index greater than 1.3. Wang, Son, and Shi (2009a) modified the switch for turbid waters for cases with index $>1.05$ and $L_{\mathrm{nw}}$ $(869 \mathrm{~nm}) \geq 0.08 \mathrm{~mW} \mathrm{~cm}{ }^{-2} \mu \mathrm{m}^{-1} \mathrm{sr}^{-1}$, as well as chl- $a \geq 1.0 \mathrm{mg} \mathrm{m}^{-3}$, which is implemented in SeaDAS version 6.4.

Ruddick, Ovidio, and Rijkeboer (2000) proposed a new technique to counter the failure of the standard algorithm over turbid waters. In the MUMM atmospheric correction technique, the assumptions of negligible water-leaving radiance at infrared bands are replaced by assumptions of spatial homogeneity of the ratio of $765 \mathrm{~nm}$ to $865 \mathrm{~nm}$ for aerosol reflectance and for water-leaving reflectance over the area of interest. These two ratios are required as calibration parameters.

\section{In situ data}

In situ data collected from three oceanographic cruises were compared to remote-sensing information.

Cruises. From November 2011 to March 2012, several cruises were organized by the Instituto Español de Oceanografía (IEO, Spanish Institute of Oceanography) to localize the exact position of the submarine eruption, to perform a periodic bathymetric survey of the area (Rivera et al. 2013), and to study the evolution of seawater anomalies produced by changes in physical-chemical parameters (Fraile-Nuez et al. 2012; Santana-Casiano et al. 2013).

Hydrography. Conductivity, temperature, pressure, oxygen, and transmittance data were collected from the surface to the seafloor at a rate of $24 \mathrm{~Hz}$ with a Seabird 9/11-plus 
CTD. Conductivity and temperature sensors were duplicated. CTD sensors were calibrated at the SeaBird laboratory before and after the project. Water samples were collected at each station with a $24 \times$ ten-litre Niskin bottle carousel.

Reduced sulphur (S) species. The reduced $\mathrm{S}$ species $\left(\mathrm{H}_{2} \mathrm{~S}, \mathrm{HS}^{-}, \mathrm{S}^{2-}, \mathrm{S}, \mathrm{SO}_{3}{ }^{2-}, \mathrm{S}_{\mathrm{x}}{ }^{2-}\right.$, $\mathrm{S}_{2} \mathrm{O}_{3}{ }^{2-}, \mathrm{S}_{4} \mathrm{O}_{6}{ }^{2-}$ ) were determined with the iodometric method (Konovalov and Romanov 2000) using an automatic potentiometric titrator equipped with a platinum electrode (Metrohm ${ }^{\mathrm{TM}}$ ). The method resulted in a standard deviation of $\pm 1 \mu \mathrm{mol} \mathrm{kg}_{\mathrm{sw}}{ }^{-1}$ (sw is sea water).

Phytoplankton pigments. chl- $a$ and phaeo-pigments (Pha) were estimated fluorometrically by using a Turner Designs bench fluorometer, previously calibrated with pure chl- $a$ (Sigma Co., St. Louis, MO, USA). Seawater samples $(500 \mathrm{ml})$ were filtered through Whatman $\mathrm{GF} / \mathrm{F}$ fibre filters and preserved by drying at $-20^{\circ} \mathrm{C}$ until analysis. On land, pigments were extracted in cold acetone $(90 \% \mathrm{v} / \mathrm{v})$ for 24 hours and analysed according to Parsons, Maita, and Lalli (1984).

\section{Data Extraction}

From visual inspection of the generated images, points were selected to extract the values of the derived geophysical data. Points were chosen to take into account the variability presented in the study area, both spatially (clear waters, productive upwelling waters, volcanic raft turbid waters, diluted volcanic plume waters, and advected-diluted upwelling waters) and temporally (start of volcanic eruption, development, and final stages). These extractions allowed, in the case of $R_{\mathrm{rs}}$ spectra, a derivation of the different colour characteristics found in the study area. Geophysical data were also extracted for comparison of in situ and remote-sensing data at match-up points.

\section{Results}

\section{SST and chl-a concentration}

Oceanographic surveys showed a thermal anomaly in the area. Its effect on the SST retrievals (not shown) was limited to the intensest periods of the event (late October to early November 2011) when several pixels were affected (up to $0.7^{\circ} \mathrm{C}$ compared with surrounding waters).

The MODIS algorithm of chl- $a$-derived unusual and unrealistic concentrations over volcanic inorganic rafts and plumes (see Figure 1). This was observed in daily, 8-day, and monthly data sets (not shown) provided by the NASA OceanColor Web. Satellite chl- $a$ concentrations within the volcanic plume were comparable to values found in upwelling areas with high local primary production.

Figure 2 shows a scatter plot of single chl- $a$ concentrations determined from in situ measurements and MODIS observations. Points included in rectangle 1 show the available data over the plume, while rectangle 2 shows the available data over unaffected waters. Data corresponding to rectangle 2 agree quite well; however points in rectangle 1 have large discrepancies.

\section{Atmospheric correction}

\section{Comparison of the NIR-SWIR approach with the STD algorithm}

At our study area, the SeaDAS NIR-SWIR implementation resulted in a moderate loss of pixels in relation to NIR, which was contrary to the results of Wang and Shi (2007) and 


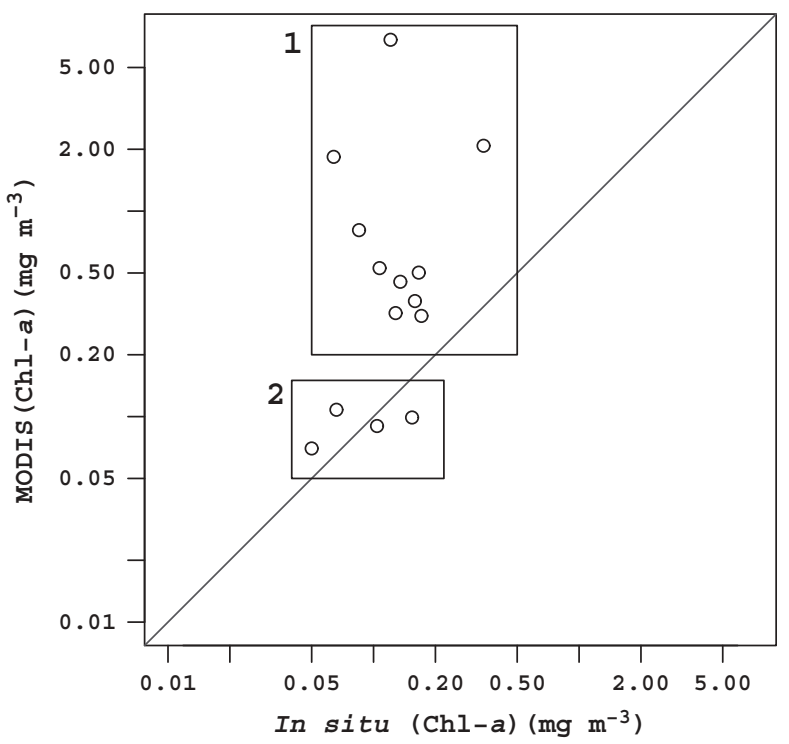

Figure 2. Scatter plot of in situ chl-a versus MODIS chl- $a$. Rectangle 1 corresponds to data over the volcanic plume and rectangle 2 corresponds to data over unaffected waters.

Wang, Son, and Shi (2009a). Werdell, Franz, and Bailey (2010) evaluated the NIR-SWIR approach relative to standard processing at Chesapeake Bay. These authors also found an increase of missing values and negative $L_{\text {nw }}$ values in the NIR-SWIR method. Comparison of derived $R_{\mathrm{rs}}$ products via scatter plots and images on different dates showed agreements between the methods of standard processing and NIR-SWIR. As an example, Figure 3(a) shows the comparison between NIR-SWIR and STD atmospheric correction with wavelengths at $412,469,531,555,667$, and $748 \mathrm{~nm}$, for the same date shown in Figure 1. A few pixels of relatively moderate turbid waters present in the area, even over upwelling regions, produced the switch from the NIR to the SWIR atmospheric correction. Examination of the turbidity index, chl- $a$ concentration, and normalized waterleaving radiance at $869 \mathrm{~nm}$ confirmed this result.

\section{Comparison of the MUMM approach with the STD algorithm}

The MUMM parameters alpha, epsilon, and gamma were adjusted for several satellite images from different dates and different regions of interest using the methodology described by Ruddick, Ovidio, and Rijkeboer (2000). The gamma slope and the alpha parameter were quite similar, close to 1.0 and 1.945 , respectively, which is close to the default values for MODIS in SeaDAS 6.4 (see Table 1). The epsilon parameter was heterogeneous in the study area and ranged from 0.973 to 1.052 , which would lead to difficulties in the use of the MUMM algorithm. Figure $3(b)$ shows the comparison between the MUMM and STD atmospheric corrections for the $R_{\mathrm{rs}}$ values at 412, 469, $531,555,667$, and $748 \mathrm{~nm}$ for the same date and areas as in Figure 1 . The $R_{\mathrm{rs}}$ values for the adjusted MUMM algorithm were slightly greater than the standard processing values, as shown by the near-perfect positive linear relationship close to the $r=1$ line in Figure $3(b)$. When tuned values were close to default SeaDAS values, scatter points lie 

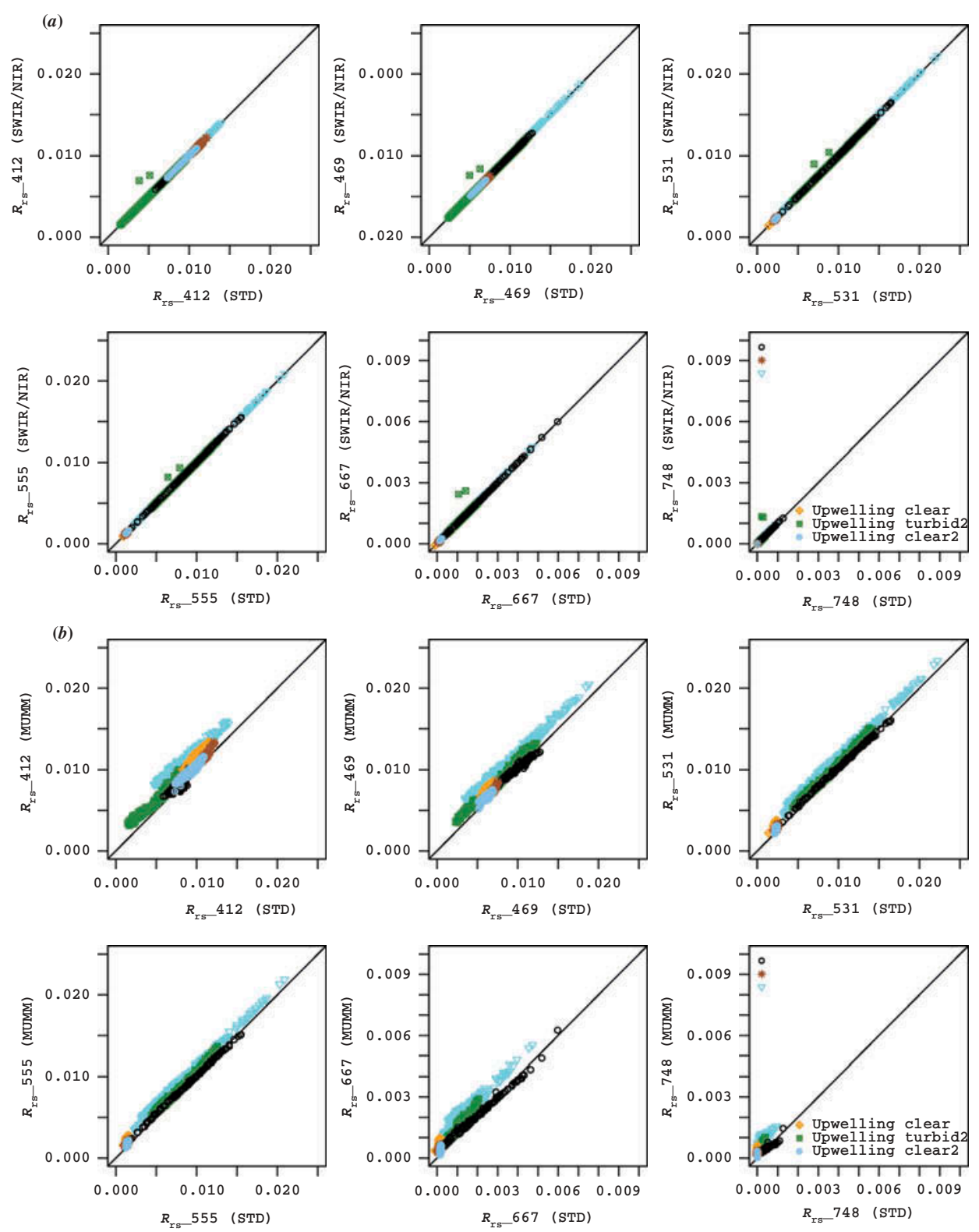

Figure 3. (a) Scatter plots of remote-sensing reflectance at different wavelengths for NIR-SWIR versus STD atmospheric corrections corresponding to areas and date shown in Figure 1. (b) Scatter plots of remote-sensing reflectance at different wavelengths for MUMM versus STD atmospheric corrections corresponding to areas and date shown in Figure 1.

over the $r=1$ line. The larger the differences between adjusted values and default values, the larger the differences between the STD and MUMM retrievals. Jamet et al. (2011) compared the atmospheric correction of turbid areas using sea-viewing wide field-of-view 
Table 1. MUMM tuning parameters alpha, epsilon, and gamma (Ruddick, Ovidio, and Rijkeboer 2000) for different areas (Hierro, Upwelling, Upwelling 2) given in Figure 1 for 2 November 2011.

\begin{tabular}{lccc}
\hline & Hierro & Upwelling & Upwelling 2 \\
\hline Alpha (turbid) & 1.945 & 1.946 & 1.945 \\
Epsilon (clear) & 1.007 & 0.973 & 1.052 \\
Gamma (clear) & 1.009 & 1.033 & 1.000 \\
\hline
\end{tabular}

sensor (SeaWIFS) data and in situ data measured in the Adriatic Sea and on the east coast of the USA. These authors found that standard SeaWIFS processing delivered better results than the MUMM algorithm. They also studied the critical impact of epsilon determination on the retrievals and pointed out that the main drawback of this algorithm is the empirical determination of the required tuned values. The scatter plots (Figure 3(b)) of $R_{\mathrm{rs}}$ showed no large differences between the STD and MUMM algorithms.

Moderate values of $R_{\mathrm{rs}}, L_{\mathrm{nw}}$, and $b_{\mathrm{b}}$ were observed in the upwelling areas and eruption plumes, suggesting moderate turbid waters in both regions. Relatively low values of $R_{\mathrm{rs}}$ and $b_{\mathrm{b}}$ were determined compared to those obtained in studies over very turbid waters (Wang, Son, and Harding 2009b; Nechad, Ruddick, and Park 2010). In Table 2, we summarize the values of $K_{\mathrm{d}}(490)$ and $b_{\mathrm{b}}$ at 443, 547, and $667 \mathrm{~nm}$ bands for the GarverSiegel-Maritorena model (GSM) (Maritorena, Siegel, and Peterson 2002) over areas considered as intense plume in the present study. Values were extracted for pixels and dates according to $R_{\mathrm{rs}}$ spectra analysed in Section 3.4. The table showed that values were moderate-low compared to those retrieved over turbid waters in previous studies. The most intense values for $K_{\mathrm{d}}(490)$ were obtained on 5 November 2011 with a mean of 0.317 and a standard deviation of 0.095 . The maximum values of $b_{\mathrm{b}}$ were also found for the same date, with a mean of 0.056 and a standard deviation of 0.026 at $443 \mathrm{~nm}$, a mean of 0.047 and a standard deviation of 0.035 at $547 \mathrm{~nm}$, and a mean of 0.038 and a standard deviation of 0.029 at $667 \mathrm{~nm}$.

Table 2. Mean and standard deviation (SD) of $K_{\mathrm{d}}(490)$ and $b_{\mathrm{b}}$ at 443,547 , and $667 \mathrm{~nm}$ for the GSM model for areas of intense volcanic plumes $\left(K_{\mathrm{d}}(490)>0.15\right)$ shown in Figure 7 (NA means not available).

\begin{tabular}{|c|c|c|c|c|c|c|c|c|}
\hline \multirow[b]{2}{*}{ Date } & \multicolumn{2}{|c|}{$K_{\mathrm{d}}(490)$} & \multicolumn{2}{|c|}{$b_{\mathrm{b}}(443)$} & \multicolumn{2}{|c|}{$b_{\mathrm{b}}(547)$} & \multicolumn{2}{|c|}{$b_{\mathrm{b}}(667)$} \\
\hline & Mean & SD & Mean & SD & Mean & SD & Mean & SD \\
\hline 13 October 2011 & 0.195 & 0.027 & 0.024 & 0.010 & 0.019 & 0.008 & 0.015 & 0.007 \\
\hline 26 October 2011 & 0.290 & 0.055 & 0.038 & 0.016 & 0.030 & 0.013 & 0.024 & 0.011 \\
\hline 2 November 2011 & 0.190 & 0.031 & 0.031 & 0.010 & 0.030 & 0.034 & 0.024 & 0.028 \\
\hline 5 November 2011 & 0.317 & 0.096 & 0.057 & 0.027 & 0.048 & 0.036 & 0.039 & 0.029 \\
\hline 13 November 2011 & 0.180 & 0.012 & 0.028 & 0.003 & 0.021 & 0.002 & 0.017 & 0.002 \\
\hline 20 November 2011 & NA & NA & NA & NA & NA & NA & NA & NA \\
\hline 7 December 2011 & 0.187 & 0.015 & 0.032 & 0.010 & 0.025 & 0.008 & 0.020 & 0.006 \\
\hline 16 December 2011 & 0.175 & 0.013 & 0.032 & 0.002 & 0.024 & 0.002 & 0.020 & 0.002 \\
\hline 27 December 2011 & 0.152 & 0.002 & 0.028 & 0.001 & 0.021 & 0.001 & 0.017 & 0.001 \\
\hline 5 January 2012 & 0.166 & 0.007 & 0.020 & 0.002 & 0.015 & 0.002 & 0.012 & 0.001 \\
\hline 10 January 2012 & 0.182 & 0.019 & 0.021 & 0.019 & 0.016 & 0.015 & 0.013 & 0.012 \\
\hline 1 February 2012 & 0.204 & 0.013 & 0.055 & 0.017 & 0.045 & 0.035 & 0.036 & 0.029 \\
\hline
\end{tabular}


The STD algorithm works well for clear and moderately turbid waters (Bailey, Franz, and Werdell 2010; Jamet et al. 2011). Uncertainties may arise from the iterative scheme, which uses chl- $a$ concentrations as input because the aforementioned unrealistic values were derived in areas with the volcanic plume. The comparisons of STD and NIR-SWIR, as well as STD and MUMM, over clear waters, plumes, and upwelling waters showed similar patterns. This suggests that STD atmospheric correction over the volcanic plumes works properly. Therefore, the STD algorithm was used in the investigations of the present article because this atmospheric correction fits the requirements and characteristics of the study area.

\section{Spatio-temporal variability}

Spatial and temporal distribution of the volcanic material expelled during the eruption is described with red-green-blue (RGB) images created using MODIS $R_{\mathrm{rs}}$ at 412 (blue channel), 531 (green channel), and $667 \mathrm{~nm}$ (red channel) (Figures 4 and 5). In Figure 4, data scaling was chosen to enhance the signal of the waters closest to the eruption focus $\left(\mathrm{R}: R_{\mathrm{rs}}(667)=[0.0-0.005], \mathrm{G}: R_{\mathrm{rs}}(531)=[0.0-0.02], \mathrm{B}: R_{\mathrm{rs}}(412)=[0.0-0.02]\right)$. Twelve scenes with a reduced spatial coverage were selected to illustrate the temporal variability of the waters containing volcanic material. Conversely, in Figure 5, scaling was chosen to enhance the visibility of the spatial extent of the weakest influenced areas of the volcanic plume $\left(\mathrm{R}: R_{\mathrm{rs}}(667)=[(-0.0015)-0.005]\right.$, G: $R_{\mathrm{rs}}(531)=[0.005-0.005], \mathrm{B}: R_{\mathrm{rs}}$ $(412)=[0.0-0.02])$. In this approach, six scenes with a larger area coverage were taken into account.

In addition, 5-day syntheses MODIS SST images and geostrophic velocities derived from altimeter data were used to study the relationship between prominent mesoscale oceanographic features identified in the region and the spatio-temporal evolution of the discoloured volcanic waters. The geostrophic velocity vectors are superimposed over MODIS RGB images in Figures 4 and 5 as well as over 5-day syntheses SST images in Figure 6. Small- and medium-size eddies are only identified in the MODIS images because Chelton, Schlax, and Samelson (2011) have shown that only eddies with spatial scales higher than $0.4^{\circ}$ can be resolved in space-based radar altimeter-derived maps. These mesoscale eddies have been labelled in the six selected binned MODIS SST images of Figure 6. It is interesting to note that all the eddies interacting with the volcanic plume were already present at the initial stages of the eruption as indicated in Figure 6(a), even though some of them were far away. The detected eddies influenced the discoloured waters at different times.

The first evidence for the onset of the volcanic eruption was on 10 October through the detection of strong harmonic seismic activity associated with magma movement called a tremor (www.ign.es). The next day, two discolourations on the ocean surface were the first visual signals of the eruptive process. However, even if the MODIS image of 12 October was cloud free over the volcano area, the first MODIS image showing the volcanic plume corresponds to 13 October 2011 (Figure 4). The reason for this could be the insufficient spatial resolution of the MODIS sensor. Over the subsequent days, the plume spread about $20 \mathrm{~km}$. From 14 to 23 October, the MODIS images were quite cloudy over volcanic eruption area, but in some images the advection of volcanic material around El Hierro was observed where the plume moved first westward and later northward.

From 23 October, clear RGB satellite images showed the presence of discoloured waters more than $175 \mathrm{~km}$ from the volcano, suggesting that an important eruptive process had occurred in the previous days. This was confirmed through visual inspection and 

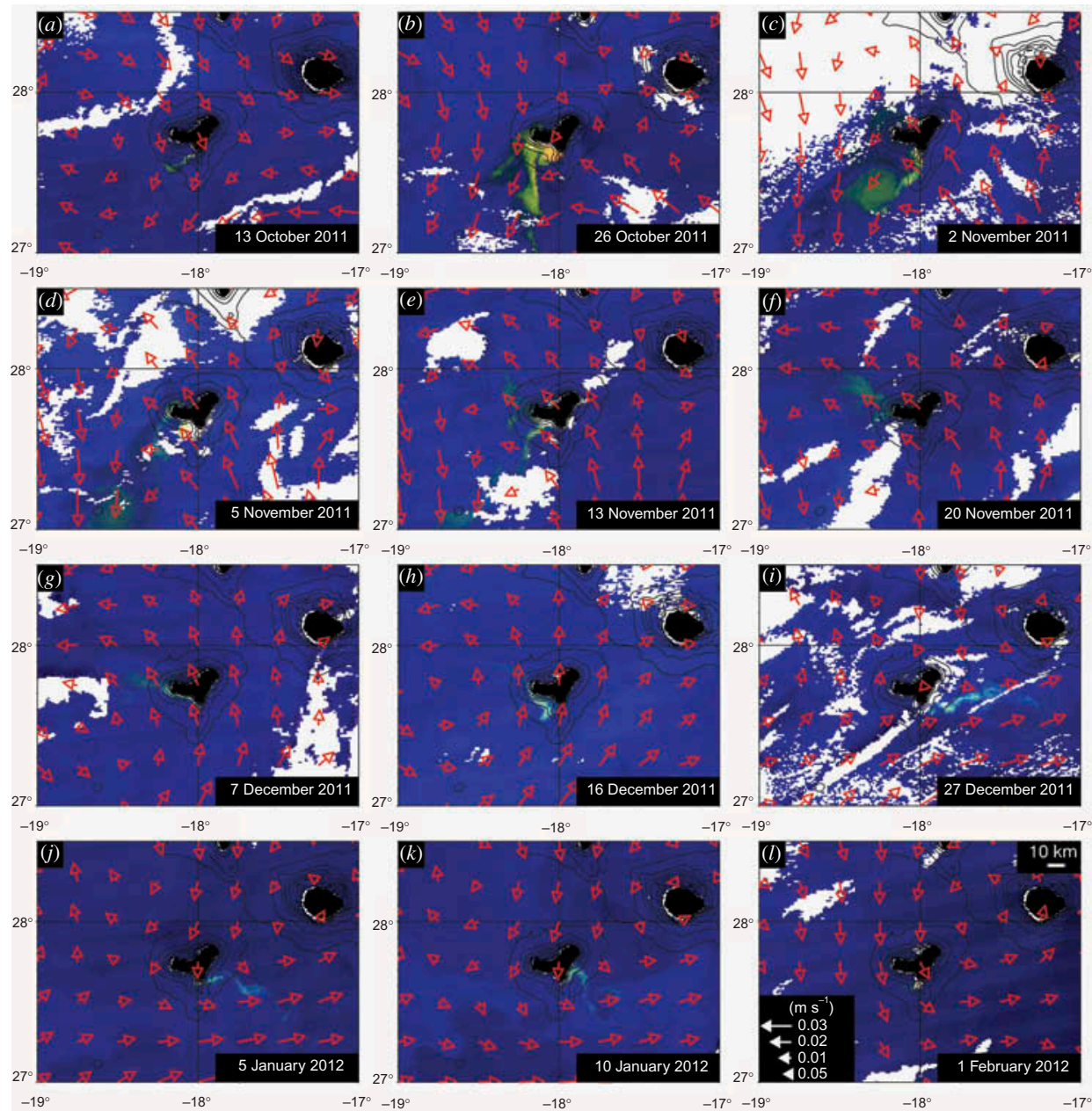

Figure 4. RGB images (R: $\left.R_{\mathrm{rs}}(667 \mathrm{~nm}), \mathrm{G}: R_{\mathrm{rs}}(531 \mathrm{~nm}), \mathrm{B}: R_{\mathrm{rs}}(412 \mathrm{~nm})\right)$ of the volcanic plume and altimeter-derived geostrophic current vectors overplotted on several dates to show their evolution near El Hierro. Scaling is chosen to enhance intense parts of the event (R: $R_{\mathrm{rs}}$ $\left.(667)=[0.0-0.005], \mathrm{G}: R_{\mathrm{rs}}(531)=[0.0-0.02], \mathrm{B}: R_{\mathrm{rs}}(412)=[0.0-0.02]\right)$.

seismic records reported by the IGN. As observed on 26 October (Figures 5(a) and 6(a)), a portion of the discoloured waters was trapped by an anticyclonic eddy, named A1, with about $60 \mathrm{~km}$ diameter and located west of El Hierro at $19.2^{\circ} \mathrm{W}$ and $28.0^{\circ} \mathrm{N}$. The relatively weak signal observed indicates that A1 provided an advective pathway for the discoloured waters during the previous cloudy period, when A1 was closer to El Hierro. MODIS SST images (Figures 6(a)-(b)) illustrate the southwestward drifting and detachment of A1 from El Hierro. This eddy separation produced an interruption of the flow and progressive weakening of the signal of the discoloured waters transported by A1 (Figure 5(a)). Therefore, the main path of the volcanic plume on 26 October was southward, in the direction indicated by the superimposed space-based radar altimeter-derived currents. A cyclonic eddy located to the southeast at approximately $17.5^{\circ} \mathrm{W}$ and $26.5^{\circ} \mathrm{N}$ $(\mathrm{C} 1$ in Figure $6(a)$ ), with about $90 \mathrm{~km}$ mean diameter at that time, promoted the 

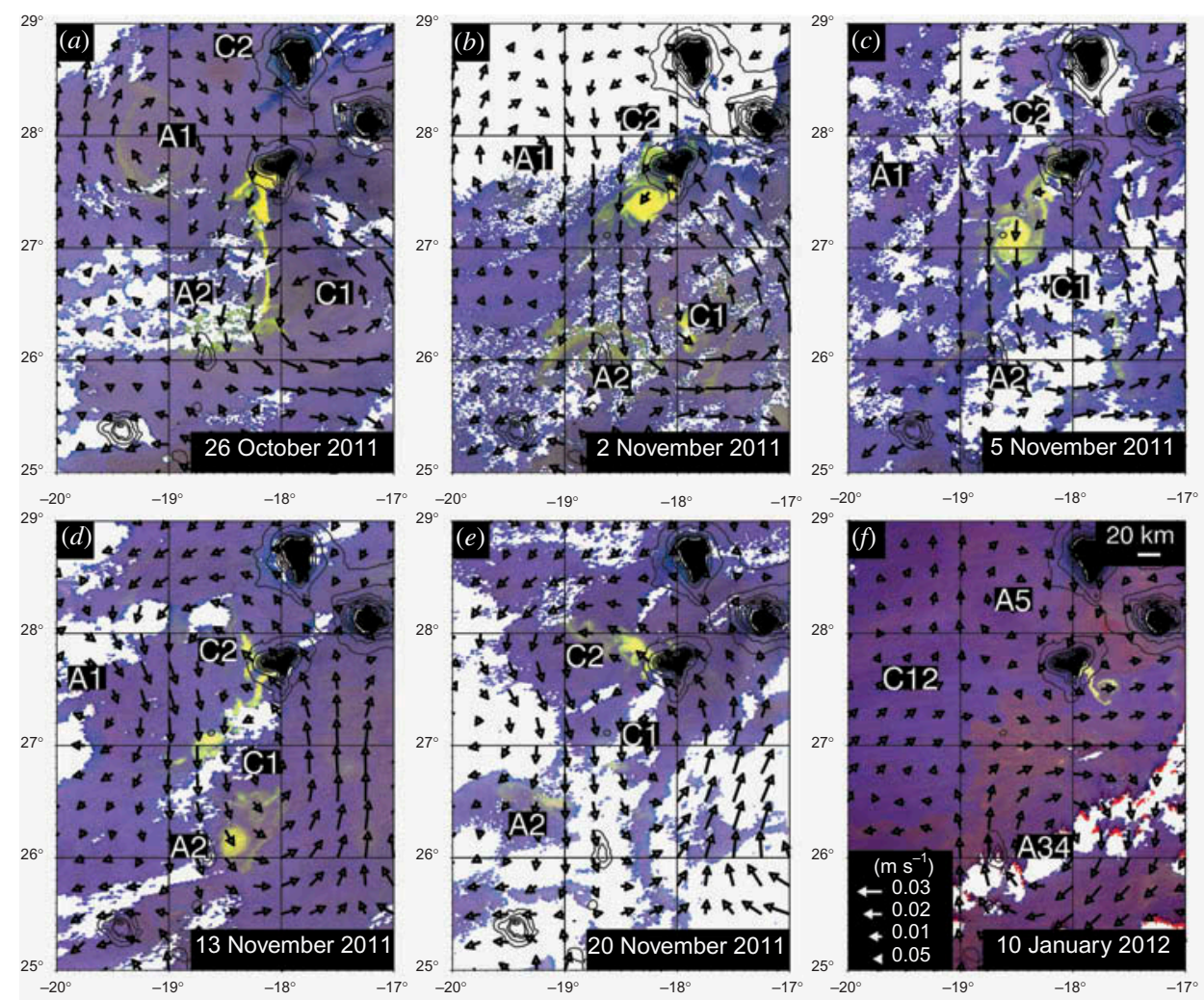

Figure 5. $\quad$ RGB images $\left(\mathrm{R}: R_{\mathrm{rs}}(667 \mathrm{~nm}), \mathrm{G}: R_{\mathrm{rs}}(531 \mathrm{~nm}), \mathrm{B}: R_{\mathrm{rs}}(412 \mathrm{~nm})\right)$ of the volcanic plume and altimeter-derived geostrophic current vectors overplotted on several dates to show their evolution far from El Hierro. Scaling is chosen to follow the spatial extent of the weakest influenced areas of the volcanic plume $\left(\mathrm{R}: R_{\mathrm{rs}}(667)=[(-0.0015)-0.005], \mathrm{G}: R_{\mathrm{rs}}(531)=[0.005-0.005], \mathrm{B}: R_{\mathrm{rs}}\right.$ $(412)=[0.0-0.02])$.

southward advection of the discoloured waters down to about $26^{\circ} \mathrm{N}$. At this latitude, a smaller anticyclonic eddy with about $35 \mathrm{~km}$ diameter, named A2 (Figure 6(a)), forced the flow to turn west (Figure 5(a)). This eddy, observed in MODIS images quite close to the southeastern side of El Hierro 1 week before the submarine eruption, drifted southwestward to its current position on 26 October.

Over the following days, the southward path was maintained but showed a convoluted route, due to the westward advance of $\mathrm{C} 1$ (Figure 6(b)). Anticyclonic eddy A2 continued its southwestward movement (Figure 6(b)), entraining more discoloured water (Figure 5(b)), and moving away the discoloured water to more than $200 \mathrm{~km}$ from the eruption centre. The dispersive action of ocean eddies diluted the volcanic plume, making it thinner and decreasing its intensity. Then, starting in November, this route was broken and a new southward flow was established coinciding with an increase in volcanic activity, as reported by IGN (Perez-Torrado et al. 2012), and observed in the intensity of RGB MODIS images (Figures $4(c)$ and $5(b)$ ). This southward flow was headed by a small anticyclonic eddy with about $30 \mathrm{~km}$ diameter that retained material expelled by the volcano (Figures $4(c)-(d)$ and Figures $5(b)-(c)$ ), allowing its identification at $26^{\circ} \mathrm{N}$ in the colour MODIS scene of 13 November (Figure 5(d)). Again, this 


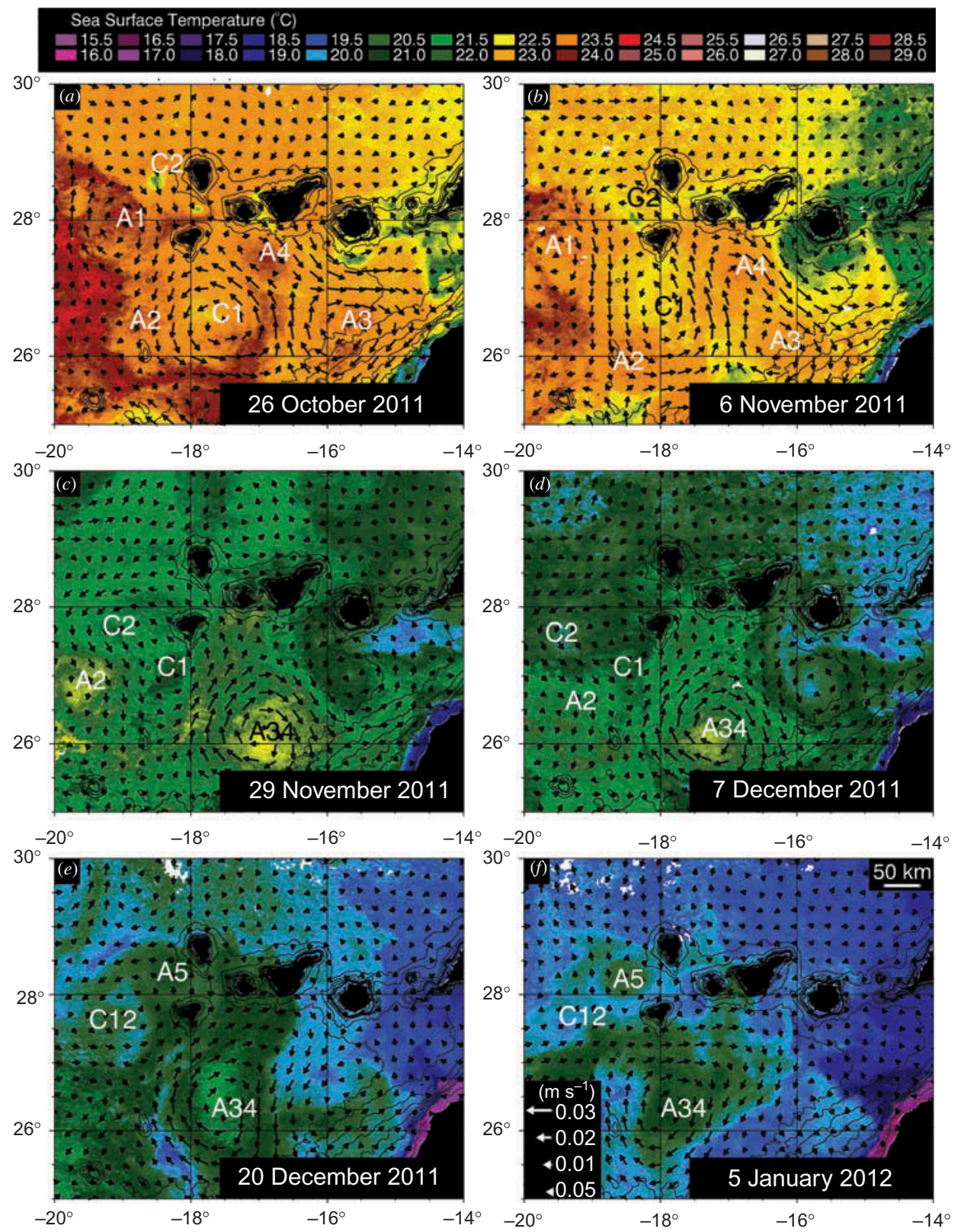

Figure 6. Five-day composite SST maps overlain with geostrophic current vectors derived from altimeter data.

image showed the convoluted path of the southward excursion of the discoloured water, reflecting the influence of mesoscale eddy $\mathrm{C} 1$ located south of El Hierro.

From 5 November, a second moderate intensity plume could be identified in the MODIS images (Figure $5(d)$ ). The plume spread northwest and later west-northwest. It coincided with the arrival of a cyclonic eddy with about $30 \mathrm{~km}$ diameter in the vicinity of 
El Hierro, named C2 (Figure 6(b)), observed initially closer to La Palma, which is located north of El Hierro (Figure 6(a)). The continuous shifting of eddy C1 westwards (Figure 6 (c)) gave rise to the interruption of the southward flow on 18 November (Figures $4(f)$ and $5(e)$ ). From this day until 16 December, eddies $\mathrm{C} 1$ and $\mathrm{C} 2$ worked together to maintain the flow of discoloured water to the west-northwest. On 20 November, this flow moved the water more than $100 \mathrm{~km}$ away from El Hierro. At the end of November, there was a decrease of the tremor signal (Perez-Torrado et al. 2012), and also a decline of the signal of discoloured waters as observed in the MODIS colour images (Figures $4(g)-(h)$ ), suggesting that volcanic activity continued but with less intensity.

From 16 December, the situation changed under the influence of a large anticyclonic eddy, A34 (Figure 6(e)), resulting from the merging of anticyclonic vortices A3 and A4 (Figures $6(a)-(b))$. After it was generated in the second half of November, A34 moved westward (Figures $6(c)-(d)$ ), and one month later its centre was found at $17.7^{\circ} \mathrm{W}$ and $26.5^{\circ} \mathrm{N}$ approximately. The centre of A34 was far from the volcano area, but the northern rim of the eddy reached El Hierro because of its great size of about $160 \mathrm{~km}$ diameter. This gave rise to an eastward flow in the area where discoloured water was expelled as indicated by altimeter-derived currents (Figures 6(e)-(f)). As a result, advection of the volcanic plume by about $40 \mathrm{~km}$ is produced in that direction (Figure 4(i)). Discoloured waters continued spreading eastward in early 2012, at least during the first half of January as observed in the MODIS images (Figures $4(j)-(k)$ and Figure 5(f)).

In the second half of January and early February, only some pixels of volcanic material were recognized in the MODIS images (e.g. Figure 4(l)). The tremor signal could not be identified clearly in seismic records from the second half of February. Finally, on 5 March, it was stated that the submarine eruption was over (Rivera et al. 2013).

\section{Spectra}

The $R_{\mathrm{rS}}$ spectra of the volcanic event on several dates are shown in Figure 7 (coincident with those of Figure 4). The volcanic plume spectra show a great variability throughout the event. The spectra were divided into three levels with $K_{\mathrm{d}}(490) \geq 0.15$ (dash-dotted curves in Figure 7), $0.13 \leq K_{\mathrm{d}}(490)<0.15$ (solid curves), and $K_{\mathrm{d}}(490)<0.13$ (dashed curves). This separation emerged from the fact that the spectra are closely related to the $K_{\mathrm{d}}$ (490) value, which is normally used as a turbidity indicator but in this article is also considered as a measure of plume intensity. The first level (dash-dotted curves) includes two shapes. The spectra of shape 1 correspond to brownish pixels (Figures $7(b)$ and $(c)$ ). These pixels are characterized by $R_{\mathrm{rs}}$ values, which do not fall abruptly from the green to red wavelength range. Only a few pixels of shape 1 were found during the event. The spectra of shape 2 of level 1 are characterized by a clear maximum at green bands $(531 \mathrm{~nm}$ or $547 \mathrm{~nm})$, which decreases quite sharply, to both blue and red bands. The second level (solid curves in Figure 7) defines the spectra of shape 3. This kind of spectra characterizes patterns with transitions from peaks at $531 \mathrm{~nm}$ to $488 \mathrm{~nm}$. The third level (dashed curves in Figure 7) corresponds to the spectra of shape 4. All spectra with a maximum at $488 \mathrm{~nm}$ belong to shape 4 , whereas the spectra gently decrease to shorter wavelengths and to green bands and, then, more sharply to red bands.

The shapes match the aerial and marine observations performed by IGN (www.ign.es). Their daily reports described the discoloured waters as teal (shape 2) or blue-green (shape 4). The spectra of shapes 2 to 4 are always consistent with the $K_{\mathrm{d}}(490)$ values. For the 

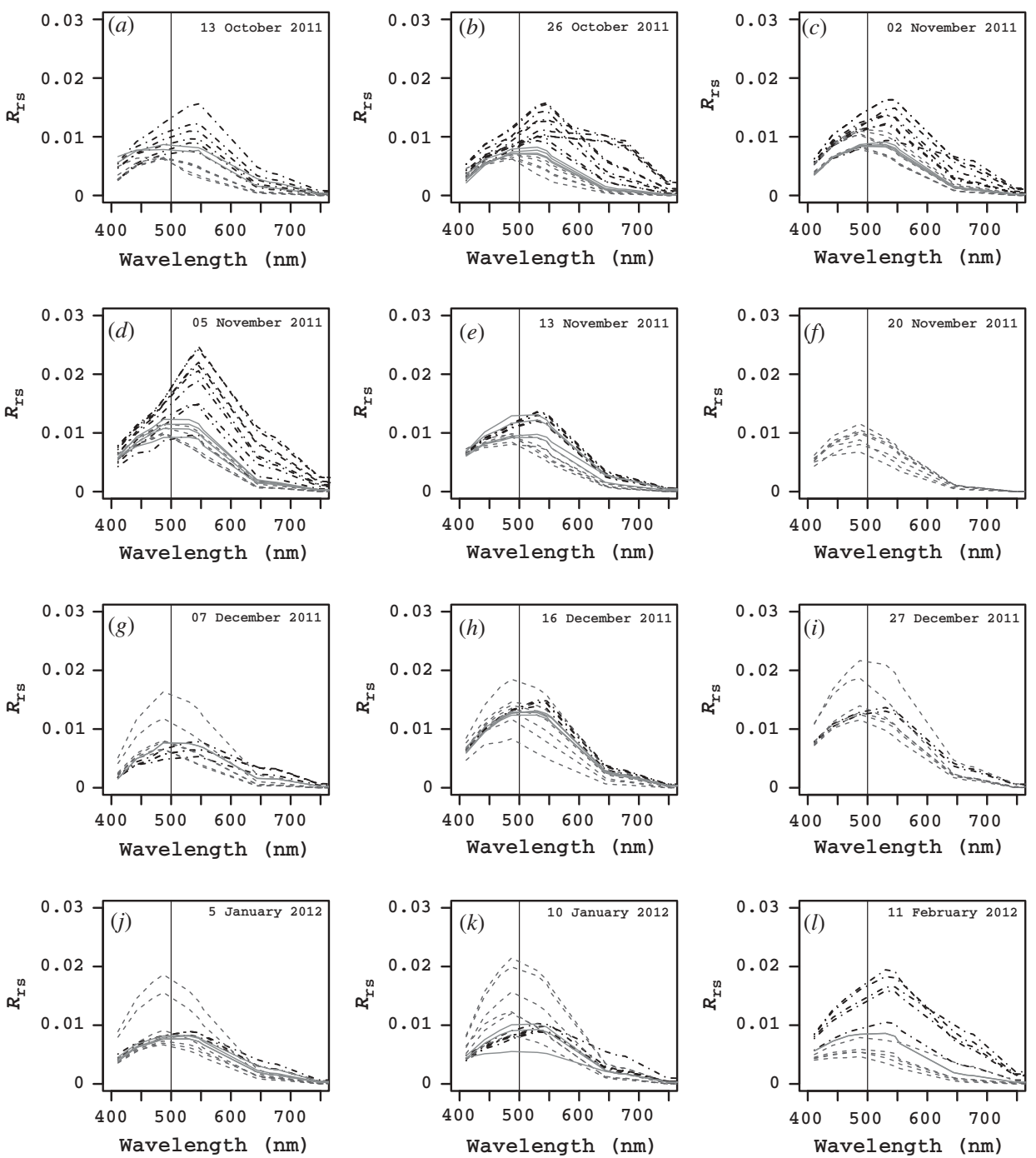

Figure 7. Spectra of remote-sensing reflectance showing variability over the volcanic plume on several dates. Dash-dotted curves: $K_{\mathrm{d}}(490) \geq 0.15$; solid curves: $0.13 \leq K_{\mathrm{d}}(490)<0.15$; dashed curves: $K_{\mathrm{d}}(490)<0.13$.

spectra of shape 2, the peak moves from $531 \mathrm{~nm}\left(K_{\mathrm{d}}(490)<0.21\right)$ to $547 \mathrm{~nm}\left(K_{\mathrm{d}}(490)\right.$ $>0.25)$ as $K_{\mathrm{d}}(490)$ increases. Brownish pixels of shape 1 do not always show $K_{\mathrm{d}}(490)$ values greater than those corresponding to shape 2 . However, their values are always clearly greater than $K_{\mathrm{d}}(490)$ values corresponding to shapes 3 and 4 . For the date with the highest intensity (5 November 2011, Figure $7(d)$ ), some spectra belonging to shape 2 maintain certain intensity at red bands due to the presence of suspended material.

The $R_{\mathrm{rs}}$ values of several spectra of shapes 3 and 4 are lower at the end of the volcanic event (Figures $7(j)$ to $(l)$ ). These spectra correspond to the mixed pattern of the volcanic eruption and increased local primary production. 


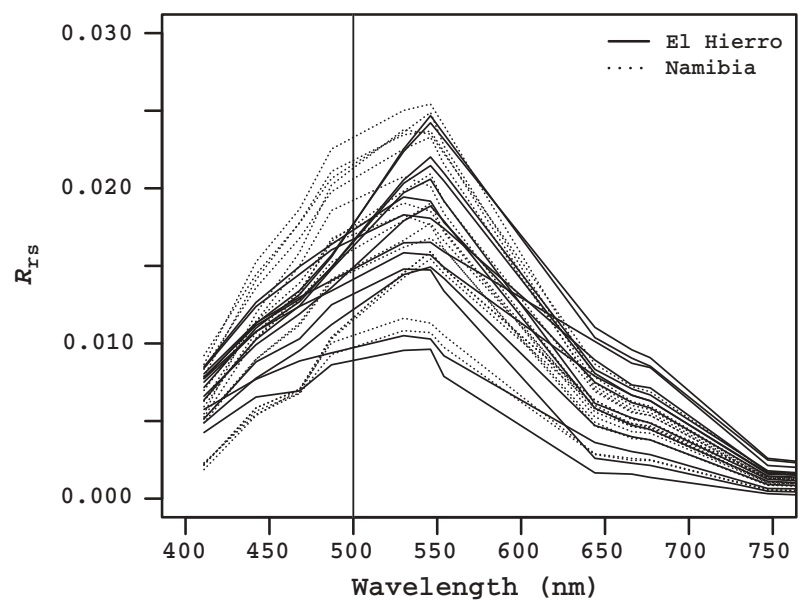

Figure 8. Spectra of remote-sensing reflectance comparing sulphide events off the Namibian coast with the El Hierro volcano eruption.

The in situ samples (Section 2.2) confirm the high concentration of sulphide compounds in the volcanic discoloured waters. Unfortunately, no real match-up of $R_{\mathrm{rs}}$ spectra on location of sulphide samples were available, but the corresponding spectra were compared with spectra of sulphide events along the Namibian coast (Ohde et al. 2007a). Spectra for both events are given in Figure 8, where the spectra were selected on the basis of similar $K_{\mathrm{d}}(490)$ values in both cases. The shapes are very similar for both events. The differences with the El Hierro spectra are due to the presence of suspended volcanic material as mentioned in the description of Figure 7(d).

Plumes of discoloured water produced by the volcanic event show colour characteristics quite similar to productive African upwelling waters. Similar spectral shapes $(2,3$, and 4) to those observed during the El Hierro event were found close to the shoreline of the upwelling area off Northwest Africa. Figure 9 shows the comparison of both kinds of spectra (El Hierro vs. coastal upwelling) as well as spectra of clear waters. The shape 2 spectra of the volcanic plume and coastal upwelling are very similar. The coastal upwelling spectra show steeper slopes between the green and red wavelength range. Also, the shape 2 spectra of the upwelling have a constant slope between $412 \mathrm{~nm}$ and $469 \mathrm{~nm}$, which is not seen for the El Hierro shape 2 spectra (cf. with Figure 9). No clear differences were found for spectra of shapes 3 and 4 .

\section{Classification scheme}

A classification scheme has been developed based on apparent optical properties. The purpose is to separate the different kinds of waters into several main groups, supplementing the information derived from $R_{\mathrm{rs}}$ spectra. Three main groups were considered: turbid, moderate, and clear waters. It was intended to separate turbid and moderate waters, according to their origin if the waters were chl- $a$ dominated (productive) or not chl- $a$ dominated (inorganic). This separation emerged from the fact that advected-diluted waters may be present from upwelling and the volcanic eruption at the same time, making it difficult to know their origin from isolated images. 

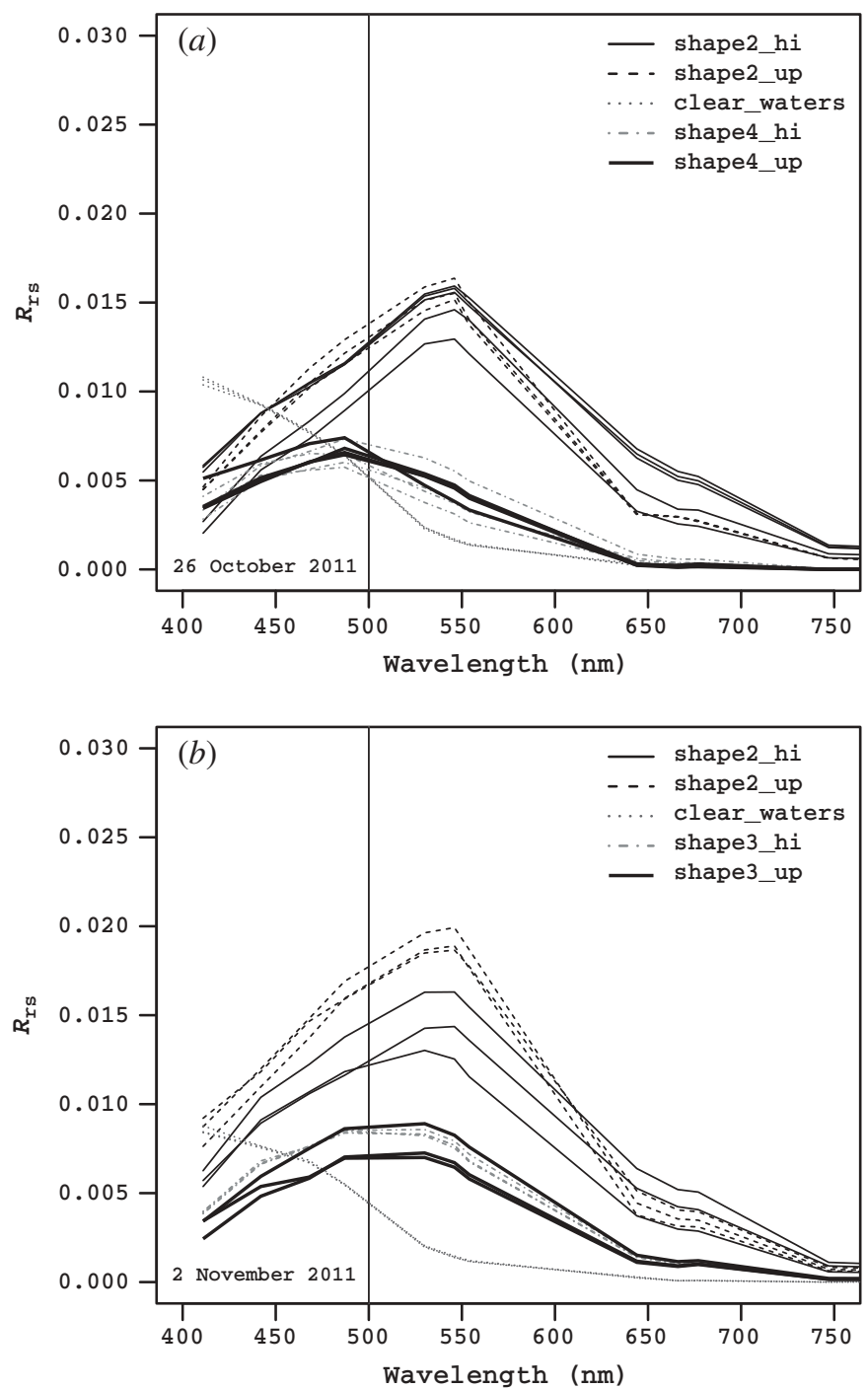

Figure 9. Spectra of remote-sensing reflectance showing similar shapes found for the El Hierro event (hi) and coastal Northwest African upwelling (up).

At the beginning of the event when the volcanic eruption was stronger, surrounding waters were clear (October-November 2011). However, in January-February 2012, the volcanic plume was weak and low local production happened as seen in chl- $a$ images (not shown).

The reflectance spectra of discoloured waters from the volcanic eruption can be quite similar to productive upwelled waters (Figure 9). Furthermore, the spectra of $R_{\mathrm{rs}}$ show significant spatio-temporal variability for the volcanic plume and upwelled productive waters.

The classification scheme separated waters into three classes according to their $K_{\mathrm{d}}$ (490) values as indicators of turbidity. 
(1) turbid waters with $K_{\mathrm{d}}(490) \geq 0.13$;

(2) moderate waters with $0.05 \leq K_{\mathrm{d}}(490)<0.13$;

(3) clear waters with $K_{\mathrm{d}}(490)<0.05$.

The limit of 0.13 corresponds to the shift of the peak of $R_{\mathrm{rs}}$ spectra from green to the blue part of the spectrum, which is related to the aforementioned shape 4 spectra. The limit of 0.05 was chosen in order to isolate clear waters.

Both classes 1 and 2 were separated into two subclasses using the ratio $R_{\mathrm{rs}}(667 \mathrm{~nm}) /$ $R_{\mathrm{rs}}(678 \mathrm{~nm})$ that takes into account the maximum absorption peak of chl- $a$ at 665 . Ratios smaller than 1.0 classified areas of chl- $a$-dominated waters (classes $1 \mathrm{~A}$ and $2 \mathrm{~A}$ ). Ratios greater than 1.0 were considered as not chl- $a$ dominated (classes $1 \mathrm{~B}$ and $2 \mathrm{~B}$ ). The ratio was noisy for clear waters (class 3 ) and did not produce consistent results. For some dates, few pixels in volcanic turbid waters were classified as chl- $a$ dominated. These pixels were placed near the volcanic cone and corresponded to 'brownish' areas (shape 1).

This straightforward scheme helped us to understand and monitor the volcanic event. Figure 10 shows an example of the classification for the same date as Figure 1. As mentioned above, chl- $a$-dominated pixels were observed in moderate discoloured waters from the volcanic event. In situ determined chl- $a$ concentrations confirmed the presence of

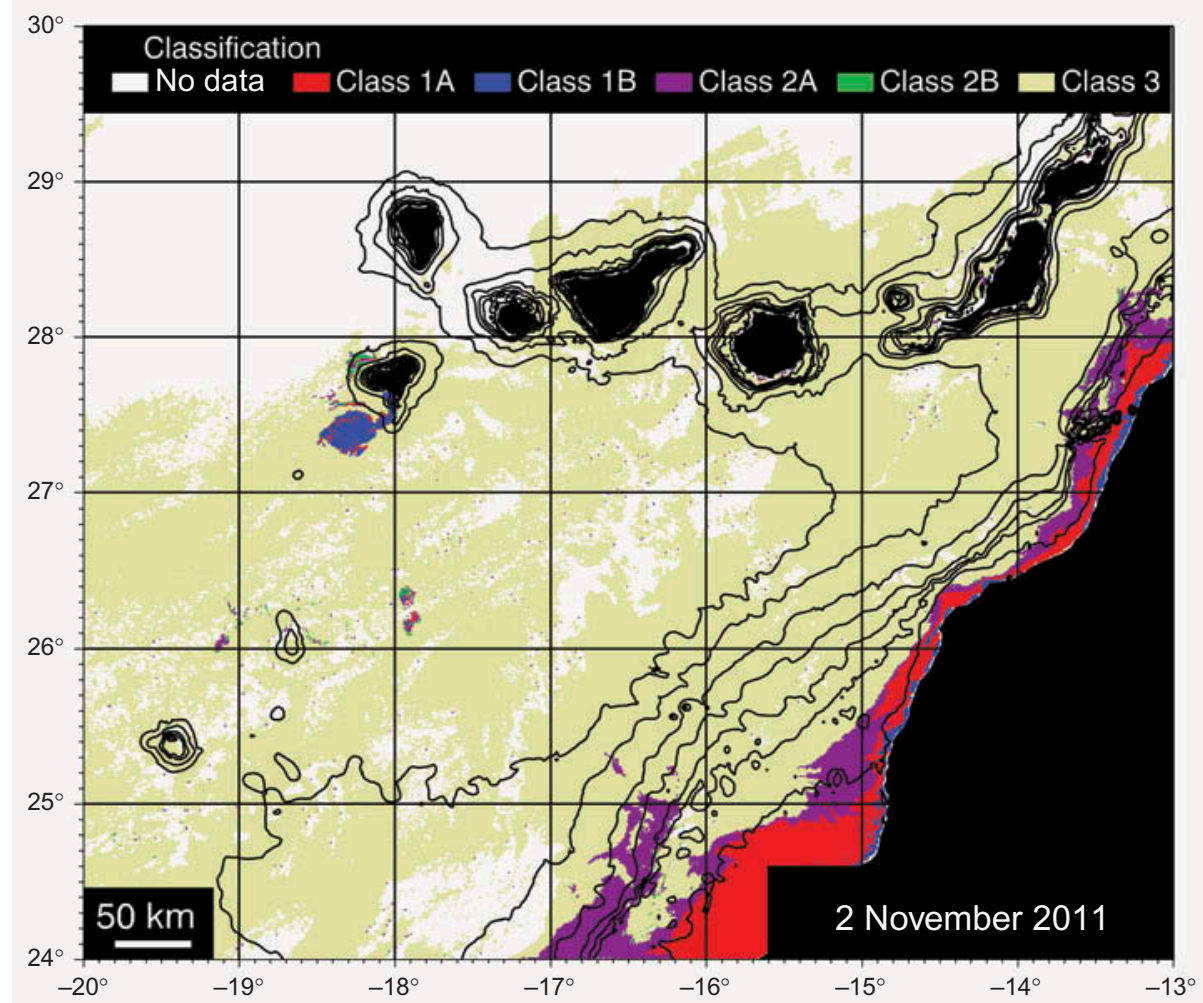

Figure 10. Example of classification scheme for 2 November 2011. Class 1A: turbid chl- $a$ dominated. Class 1B: turbid not chl- $a$ dominated. Class 2A: moderate turbid chl- $a$ dominated. Class 2B: moderate turbid not chl- $a$ dominated. Class 3: clear waters. 
chl- $a$ in the diluted volcanic discoloured waters. In the core areas of the volcanic plume, the in situ data also confirmed the wrong high chl- $a$ concentrations derived by MODIS processing. It was found that the differences increased if the event intensity increased (compare Figure 1 with Figure 10).

\section{Discussion}

In this study, the spatial and temporal variability of the El Hierro submarine volcanic plume has been derived from a combined analysis of different remote-sensing data. IGN did not provided tremor data; however, graphical visualizations are available at the IGN website (http://www.ign.es/ign/resources/volcanologia/HIERRO.html). A tremor started on 10 October 2011, 3 days prior to the first MODIS image showing discoloured waters. The most intense plume was seen at the end of October, early November; however, tremor visualizations available at IGN showed the most intense tremor values during November. Tremor intensity decreased in December becoming intermittent, the plume development showed a similar pattern. Starting in mid-February, the signal became flat and no discoloured waters were detected. During the initial most active phase of the eruption, which lasted from 10 October until the end of November, the discoloured waters containing volcanic material were identified more than $200 \mathrm{~km}$ away from the volcano, even approaching areas where upwelled waters transported by upwelling filaments were present. This fact made it difficult to distinguish between discoloured volcanic waters and those coming from the upwelling, in isolated chl- $a$ images (see the area marked with a black square in Figure 1).

In this active period, the material expelled by the volcano into the oceanic water column was spread by strong currents near to El Hierro, which were associated with mesoscale eddies. The currents forced the volcanic plume in three different directions: first to the west, then to the south, and finally to the northwest.

The following phase, from the end of November until the first half of January, was characterized by a drop in the volcanic activity. In this phase, a decrease of the spatial extent of the volcanic plume and a reduction of the signal intensity in the MODIS RGB images was observed. In this period, the spatial orientation of the plume changed from a westward to eastward direction. Finally, the last phase, from the second half of January until the end of the submarine eruption on 5 March, MODIS data showed the presence of discoloured waters only near to the centre of the eruption.

All these changes in the orientation of the volcanic plume can be satisfactorily explained through the influence exerted by mesoscale eddies. At this point, it is important to take into account that El Hierro is the smallest, and southwesternmost, of the Canary Islands. Besides small locally generated eddies, the waters where the eruption took place were affected by larger remote eddies arriving at different times. These large-size coherent eddies could reach El Hierro, either coming from the east on to the southern side of the island or coming from the north on to the western side of the island. In any case, these eddies played an important role in the transport of the volcanic discoloured waters within the ocean environment, which was forced by different processes: advection produced by currents associated with eddies, retention produced by the circulatory motion of the flow within these coherent structures, and dispersion due to mixing produced by mesoscale and also more ephemeral small-scale eddies.

The comparison of the STD, MUMM, and NIR-SWIR atmospheric correction schemes emerged from the nature of the target event, which produced anomalous turbidity-releasing inorganic materials. Therefore, it was necessary to investigate the possible 
impact of this inorganic material on atmospheric correction schemes. The comparison of the three algorithms verified the use of standard atmospheric processing scheme to be suitable for the investigation of a volcanic eruption in the study area. Mantas, Pereira, and Morais (2011) also used the STD approach for a volcanic event, which produced similar $R_{\mathrm{rs}}$ values to the El Hierro event. From a remote-sensing point of view, this event can be considered as moderate in intensity compared with other turbid waters. The $R_{\mathrm{rs}}$ values scarcely reached up to 0.025 for any MODIS band. Also, during the event, the $K_{\mathrm{d}}(490)$ values exceeded 0.4 for only a few pixels and days. This is close to 0.3 , a value considered by some authors as an upper threshold for moderately turbid waters (Shi and Wang 2010). $b_{\mathrm{b}}$ values at $667 \mathrm{~nm}$ barely exceeded 0.05 in maximum intensity during the event.

Shi and Wang (2011) determined $R_{\mathrm{rs}}$ values of up to 0.06 , and $K_{\mathrm{d}}(490)$ values of up to 0.15 for a volcanic event in the southern tropical Pacific. It must be noted that these authors used the NIR-SWIR approach for the atmospheric correction. Mantas, Pereira, and Morais (2011) found similar $R_{\mathrm{rs}}$ values for a volcanic event in Tonga in 2006 as determined in the present work for the El Hierro event. The main difference of the Tonga event was the extension of pumice rafts (corresponding to shape 1 in the present study, brownish colour) that spread about $50 \mathrm{~km}$ wide. The brownish rafts of the El Hierro event, not always present, only extended over a few kilometres. However, from late October to mid-November, the extension of plumes of discoloured water reached areas far from the volcano (Figures 1 and 5). It should be considered that, even during less intense periods, the event noticeably affected the determination of chl- $a$, using remote sensing.

The thermal anomaly caused by the volcanic activity, which was determined by the oceanographic surveys, did not spread over the surface layers and was only located above the volcano cone. Thermal anomalies were also detected (late October early November) by thermal airborne camera during several cruises conducted throughout the event. Maximum recorded temperatures reached $35^{\circ} \mathrm{C}$; however, the influenced surface water did not spread more than $50 \mathrm{~m}$ (P. Hernández, personal communication, 2013). The spatial resolution of the sensor and the extent of the affected area constrained anomalies in the SST satellite retrievals as found by Shi and Wang (2011) during a volcanic eruption in the southern tropical Pacific. Chl- $a$ retrievals over unaffected waters agreed well with the in situ data (Figure 2, rectangle 2). But the chl- $a$ concentrations were overestimated in waters discoloured by volcanic material (Figure 2, rectangle 1). The anomalously high chl- $a$ concentrations derived from MODIS in the volcanic plume were caused by the blue-green shift of the spectra, which was a result of the absorption properties of volcanic ash in the water column. This shift produced spectra shapes that were similar to those found in some areas of the Northwest African upwelling. Therefore, the MODIS algorithm, which is based on $R_{\mathrm{rs}}$ values, produced nearly the same chl$a$ values in the upwelling region and the volcanic plume area. But the field measurements showed much lower chl- $a$ concentrations in the volcanic plume. Therefore, the MODISderived chl- $a$ values cannot be taken into account in areas influenced by volcanic material. There are three possible reasons for slightly higher chl- $a$ concentrations in the study region if they are not affected by volcanic eruptions. First, the Canary Islands are located in the coastal transition zone and, therefore, are under the influence of chlorophyll-rich waters resulting from the coastal upwelling off Northwest Africa (Brink and Cowles 1991; Polovina et al. 2001; Barton et al. 2004). Second, the Canary archipelago disturbs the incident oceanic flow over the islands increasing the mesoscale activity (Arístegui et al. 1994; Barton et al. 2004) and modifying chl- $a$ concentrations around the islands (Arístegui et al. 1997). The third reason is a result of winter mixing processes (Schmoker, Arístegui, and Hernández 2012). 
The similarity between African upwelling spectra and the El Hierro ones could be explained by their occurrence near the coast, because they could be affected by inorganic material from sedimentary resuspension, as well as by yellow substances and chl- $a$, which cause high absorption in the blue spectral range. The concentrations of yellow substances and chl- $a$ in the upwelling area are normally higher near the coast than in the open sea (e.g. Ohde, Siegel, and Gerth 2007b). Therefore, the reflectance maximum shifted from blue to green in the cross-shore direction to the coast. Differences were found in both areas for spectra of shape 2 where the upwelling spectra were characterized by a steeper slope between the green and red wavelength ranges and a constant slope between $412 \mathrm{~nm}$ and $469 \mathrm{~nm}$. However, no differences were found for shapes 3 and 4 . The discolouration for shapes 3 and 4 corresponded to moderate-low $K_{\mathrm{d}}(490)$ values, which made it difficult to discriminate those restrained intensities. Although similar spectra shapes were found in the African upwelling region and the El Hierro plume, they were caused by different optical active water constituents.

The amount of brownish pixels in the El Hierro plume was low, even nonexistent for many days. In spite of variability, discarding the brownish pixels (shape 1), two main shapes were identified for pixels belonging to the intense plume (shape 2) with peaks at green bands $(531 \mathrm{~nm}-547 \mathrm{~nm})$ and to the moderate plume (shape 4) with a peak at $489 \mathrm{~nm}$. A third one (shape 3) was determined, which corresponded to the transition of spectra of shapes 2 to 4 . The characteristics of the material expelled by the volcano and the intensity of the eruption changed throughout the El Hierro episode, as in other volcanic events (Urai and Machida 2005; Mantas, Pereira, and Morais 2011).

The $K_{\mathrm{d}}(490)$ values used in the present work were processed with the standard algorithm implemented in SeaDAS 6.4. The values of $K_{\mathrm{d}}(490)$ brownish pixels, which were not consistent with event intensity, can be related to the $R_{\mathrm{rs}}(489 \mathrm{~nm})$ and $R_{\mathrm{rs}}(547 \mathrm{~nm})$ ratio used by the $K_{\mathrm{d}}(490)$ SeaDAS algorithm. The actual $K_{\mathrm{d}}(490)$ values for these few pixels were probably underestimated, as suggested by Wang, Son, and Harding (2009b) because the algorithm was not developed for turbid waters. Wang, Son, and Harding (2009b) found a better performance for the standard algorithm for clear ocean waters with $K_{\mathrm{d}}(490)<0.3$. However, underestimates of up to three times were found for higher $K_{\mathrm{d}}$ (490) values. The brownish pixels corresponded to areas surrounding the centre of the volcanic eruption, where higher turbidity was expected and the $R_{\mathrm{rs}}$ spectra showed significant values in the MODIS red bands. The blue to green ratio-based algorithm for $K_{\mathrm{d}}(490)$ of SeaDAS failed for these turbid brownish pixels. These areas were characterized by a significant presence of water constituents that scattered in the red wavelength range, suggesting more appropriate algorithms based on a blue to red ratio. However, during the event, relatively few pixels met those conditions. The $R_{\mathrm{rs}}$ values in the NIR bands hardly reached 0.003 (Figures $7(b),(c),(d)$, and $(l)$ ). The size of the area covered by $R_{\mathrm{rs}}(748 \mathrm{~nm})$ values greater than 0.002 was about $16.5 \mathrm{~km}^{2}$ for one of the most intense plumes on 26 October. However, for the same date, the area covered by $K_{\mathrm{d}}(490)$ values greater than 0.05 was about $2200 \mathrm{~km}^{2}$. In the present study, only a few pixels on some dates exceed the $K_{\mathrm{d}}(490)$ value of 0.3 . Moreover, for the intense event on 5 November 2011 , most of the pixels with $K_{\mathrm{d}}(490)>0.3$ corresponded to the spectra of shape 2 characterized by intense peaks at $547 \mathrm{~nm}$ (at $531 \mathrm{~nm}$ for lower $K_{\mathrm{d}}(490)$ values) and low $R_{\mathrm{rs}}$ values in the red MODIS bands. These findings suggest that an algorithm that uses a blue to green ratio (489 $\mathrm{nm}$ to $547 \mathrm{~nm}$ ) such as SeaDAS is more appropriate for the El Hierro event.

The reduced sulphur species, which were detected in the volcanic plume during the oceanographic cruises, discoloured characteristically the surface waters. The surface 
waters affected by the volcano emissions had a sulphur concentration ranging from $50 \mu \mathrm{mol} \mathrm{kg}{ }^{-1}$ to $132 \mu \mathrm{mol} \mathrm{kg}{ }^{-1}$. The highest concentrations in the surface waters were measured in December. In the water column, the higher concentrations were found at $75-100 \mathrm{~m}$ depth reaching maximum values of $476 \mu \mathrm{mol} \mathrm{kg}{ }^{-1}$ at $75 \mathrm{~m}$ depth on 17 November. In February 2012, sulphur was detected only in the surface waters above the volcano with a concentration of $40 \mu \mathrm{mol} \mathrm{kg}$. In April 2012, reduced sulphur species were present below the detection limit. In the Namibian waters, milky turquoise discolourations can be caused by sulphide events or by coccolithophore blooms (Weeks et al. 2004; Siegel et al. 2007; Ohde et al. 2007a; Ohde and Mohrholz 2011). Although the origin of the sulphur plumes is different (volcanic event vs. upwelling or eruptions of hydrogen sulphide-enriched waters), the cause of the discolouration of the water is the oxidation of hydrogen sulphide. Despite their different nature, the $R_{\mathrm{rs}}$ spectra of sulphide events off Namibia and at El Hierro (shape 2) are very similar (see Figure 8). Some disagreements were found for pixels that were affected by volcanic suspended matter near the areas of the eruption centre.

The spectral peaks of volcanic events investigated by Shi and Wang (2011) as well as by Mantas, Pereira, and Morais (2011) were at $488 \mathrm{~nm}$. The shape of the spectra observed by Mantas, Pereira, and Morais (2011) was constant and very similar to the spectra of shape 4 found in the present study. However, two shapes were identified by Shi and Wang (2011).

Frogner, Gíslason, and Óskarsson (2001) studied an event with volcanic ash in sea water in the region of Iceland. They showed that the ash from volcanoes can release substantial amounts of macro- and micro-nutrients such as $\mathrm{PO}_{4}{ }^{3-}, \mathrm{Si}, \mathrm{Fe}, \mathrm{Zn}, \mathrm{Mn}, \mathrm{Ni}, \mathrm{Co}$, and $\mathrm{Cu}$. Duggen et al. (2007) verified by biogeochemical experiments and satellite data that volcanic ash in a subduction zone can stimulate phytoplankton growth. Mantas, Pereira, and Morais (2011) confirmed a posterior algae bloom after a volcanic event. The criterion used for chl- $a$ absorption in terms of $R_{\mathrm{rs}}$ ratios of $667 \mathrm{~nm}$ to $678 \mathrm{~nm}$, which separated turbid waters due to the volcanic material from those due to biological production, produced some pixels in the El Hierro area classified as chl- $a$ dominated. Those pixels were placed on the edge of the intense plumes and were more frequently observed over diluted moderate plumes (see Figure 10). The submarine volcanic eruption of El Hierro released important amounts of $\mathrm{Fe}(\mathrm{II})$ and nutrients into the seawater (SantanaCasiano et al. 2013). Thus, the possibility for nutrient enrichment has been confirmed. Nevertheless, taking into account chl- $a$ found in the oceanographic field cruises and derived by remote sensing in advected plumes, this effect should be considered as low. Primary production could be constrained by the physical-chemical perturbations (FraileNuez et al. 2012).

One important characteristic in the $R_{\mathrm{rs}}$ spectra was the change of the slope sign from 667 to $678 \mathrm{~nm}$ in upwelling areas, which was not observed in turbid raft areas. This characteristic originated from the absorption peak of chl- $a$ and allowed the identification of chl-a-dominated pixels in the classification scheme using the ratio of these bands. However, the ratio failed for some pixels in the inner core of the volcano where scattering in the red MODIS bands, forced by suspended matter, was important. The classification introduced here has helped to understand and to follow the evolution of the plume. In areas with moderate turbidity (class 2 ), the ratio of pixels classified as chl$a$ dominated (class 2A) to pixels identified as non-chl- $a$ dominated (class 2B) increased with the spatio-temporal evolution of the plume. This could be related to the relaxation of the stressing conditions produced immediately after the volcanic eruptions that prevented phytoplankton development. The presence of non-chl-a-dominated pixels in 
the coastal upwelling (class 1B) can be related to sediment resuspension and bottom backscattering in shallow waters.

\section{Conclusions}

An assessment of three atmospheric corrections has led to the conclusion that the use of the SeaDAS standard atmospheric correction for MODIS is the most suitable approach for the El Hierro submarine volcanic eruption in late 2011 until early 2012.

As far as ocean colour processing is concerned, the intensity of the event can be considered to be moderately turbid according to the $K_{\mathrm{d}}(490)$ and $b_{\mathrm{b}}$ values.

Field data corroborated the failure of MODIS chl- $a$ algorithms over the discoloured waters associated with the volcano. At the same time, the in situ data confirmed the presence of low chl- $a$ over the advected plume.

The spatio-temporal variability of the volcanic plume is strongly related to the presence of mesoscale vortices in the vicinity of the eruption area. Changes in the orientation and direction of the waters transporting volcanic material were linked to changes in the mesoscale activity in the region of interest, as observed through the combined use of colour, SST, and altimeter satellite data.

$R_{\mathrm{rs}}$ spectra led to the classification of different kinds of waters present in the area, allowing their comparison with other similar events. The spectral shapes obtained over the plume were closely related to the value of $K_{\mathrm{d}}(490)$, an indicator of water turbidity. Oceanographic survey samples collected inside of the plume evidenced the high concentration of sulphur compounds. According to their composition, El Hierro and Namibia sulphide events show similar spectra. On the other hand, with respect to other volcanic submarine eruptions (e.g. Tonga), similar spectral shapes were found.

The classification schema based on $K_{\mathrm{d}}(490)$ and the ratio of $R_{\mathrm{rs}} 667 \mathrm{~nm}$ to $R_{\mathrm{rs}} 678 \mathrm{~nm}$ permit the characterization and tracking of the event. The number of areas classified as productive water increased throughout the spatio-temporal evolution of the plume.

\section{Acknowledgements}

We thank the OceanColor Web for the providing of MODIS data and SeaDAS package (http:// oceancolor.gsfc.nasa.gov/) as well as for the support via the OceanColor Web Forum. We also thank the R-Cran project (http://www.r-project.org/) for providing the R software. The altimeter products were produced by SSALTO/DUACS (Segment Sol multimissions d'ALTimétrie, d'Orbitographie et de localisation précise/Data Unification and Altimeter Combination System) and distributed by AVISO (Archiving, Validation and Interpretation of Satellite Oceanographic data) (http://www.aviso.oceanobs.com/duacs/), with support from CNES (Centre national d'études spatiales)

\section{References}

Adams, D. K., D. J. McGillicuddy Jr, L. Zamudio, A. M. Thurnherr, X. Liang, O. Rouxel, C. R. German, and L. S. Mullineaux. 2011. "Surface-Generated Mesoscale Eddies Transport DeepSea Products from Hydrothermal Vents." Science 332: 580-583. doi:10.1126/science.1201066.

Arístegui, J., P. Sangrá, S. Hernández-León, M. Cantón, A. Hernández-Guerra, and J. L. Kerling. 1994. "Island-Induced Eddies in the Canary Islands." Deep Sea Research Part I: Oceanographic Research Papers 41 (10): 1509-1525. doi:10.1016/0967-0637(94)90058-2.

Arístegui, J., P. Tett, A. Hernández-Guerra, G. Basterretxea, M. F. Montero, K. Wild, P. Sangrá, S. Hernández-Leon, M. Canton, J. A. García-Braun, M. Pacheco, and E. D. Barton. 1997. "The Influence of Island-Generated Eddies on Chlorophyll Distribution: A Study of Mesoscale 
Variation around Gran Canaria." Deep Sea Research Part I: Oceanographic Research Papers 44 (1): 71-96. doi:10.1016/S0967-0637(96)00093-3.

Bailey, S. W., B. A. Franz, and P. J. Werdell. 2010. "Estimation of Near-Infrared Water-Leaving Reflectance for Satellite Ocean Color Data Processing." Optics Express 18 (7): 7521-7527. doi:10.1364/OE.18.007521.

Barton, E. D., J. Arístegui, P. Tett, and E. Navarro-Pérez. 2004. "Variability in the Canary Islands Area of Filament-Eddy Exchanges." Progress in Oceanography 62: 71-94. doi:10.1016/j. pocean.2004.07.003.

Brink, K. H., and T. J. Cowles. 1991. "The Coastal Transition Zone program." Journal of Geophysical Research 96: 14637-14647. doi:10.1029/91JC01206.

Bryan, S. E., A. Cook, J. P. Evans, P. W. Colls, M. G. Wells, M. G. Lawrence, J. S. Jell, A. Greig, and R. Leslie. 2004. "Pumice Rafting and Faunal Dispersion during 2001-2002 in the Southwest Pacific: Record of a Dacitic Submarine Explosive Eruption from Tonga." Earth and Planetary Science Letters 227: 135-154. doi:10.1016/j.epsl.2004.08.009.

Carracedo, J. C., F. Perez-Torrado, A. Rodríguez-González, V. Soler, J. L. Fernández-Turiel, V. R. Troll, and S. Wiesmaier. 2012. "The 2011 Submarine Volcanic Eruption in El Hierro (Canary Islands)." Geology Today 28 (2): 53-58. doi:10.1111/j.1365-2451.2012.00827.x.

Chelton, D. B., M. G. Schlax, and R. M. Samelson. 2011. "Global Observations of Nonlinear Mesoscale Eddies." Progress in Oceanography 91: 167-216. doi:10.1016/j. pocean.2011.01.002.

Duggen, S., P. Croot, U. Schacht, and L. Hoffmann. 2007. "Subduction Zone Volcanic Ash Can Fertilize the Surface Ocean and Stimulate Phytoplankton Growth: Evidence from Biogeochemical Experiments and Satellite Data." Geophysical Research Letters 34 (1): 1-5. doi:10.1029/2006GL027522.

Fraile-Nuez, E., M. González-Dávila, J. M. Santana-Casiano, J. Arıstegui, I. J. Alonso-González, S. Hernández-Leon, M. J. Blanco, A. Rodriguez-Santana, A. Hernández-Guerra, M. D. GeladoCaballero, F. Eugenio, J. Marcello, D. De Armas, J. F. Domınguez-Yanes, M. F. Montero, D. R. Laetsch, P. Velez-Belchı, A. Ramos, A. V. Ariza, I. Comas-Rodriguez, and V. M. BenitezBarrios. 2012. "The Submarine Volcano Eruption at the Island of El Hierro: Physical-Chemical Perturbation and Biological Response." Scientific Reports 2 (486). doi:10.1038/srep00486.

Frogner, P., S. R. Gíslason, and N. Óskarsson. 2001. "Fertilizing Potential of Volcanic Ash in Ocean Surface Water." Geology 29: 487-490. doi:10.1130/0091-7613(2001)029<0487: FPOVAI $>2.0 . \mathrm{CO} ; 2$.

Jamet, C., H. Loisel, C. P. Kuchinke, K. Ruddick, G. Zibordi, and H. Feng. 2011. "Comparison of Three SeaWIFS Atmospheric Correction Algorithms for Turbid Waters Using AERONET-OC Measurements." Remote Sensing of Environment 115: 1955-1965. doi:10.1016/j. rse.2011.03.018.

Konovalov, S. K., and A. S. Romanov. 2000. "Spectrophotometric and Iodometric Methods for the Detection of Hydrogen Sulfide in the Black Sea: Comparison of the Results of Analysis." Physical Oceanography 10: 365-377. doi:10.1007/BF02519307.

Macau-Vilar, F. 1963. "Sobre El Origen Y Edad De Las Islas Canarias: El Archipiélago Equivalente." Anuario De Estudios Atlánticos 9: 467-518.

Mantas, V. M., A. J. S. C. Pereira, and P. V. Morais. 2011. "Plumes of Discolored Water of Volcanic Origin and Possible Implications for Algal Communities. the Case of the Home Reef Eruption of 2006 (Tonga, South-West Pacific Ocean)." Remote Sensing of Environment 115: 1341-1352. doi:10.1016/j.rse.2011.01.014.

Maritorena, S., D. A. Siegel, and A. Peterson. 2002. "Optimization of a Semi-Analytical Ocean Color Model for Global Scale Applications.” Applied Optics 41 (15): 2705-2714. doi:10.1364/ AO.41.002705.

Nechad, B., K. G. Ruddick, and Y. Park. 2010. "Calibration and Validation of a Generic Multisensor Algorithm for Mapping of Total Suspended Matter in Turbid Waters." Remote Sensing of Environment 114: 854-866. doi:10.1016/j.rse.2009.11.022.

Ohde, T., and V. Mohrholz. 2011. "Interannual Variability of Sulphur Plumes off the Namibian Coast." International Journal of Remote Sensing 32 (24): 9327-9342. doi:10.1080/ 01431161.2011.554455.

Ohde, T., H. Siegel, and M. Gerth. 2007b. "Validation of MERIS Level-2 Products in the Baltic Sea, the Namibian Coastal Area and the Atlantic Ocean." International Journal of Remote Sensing 28: 609-624. doi:10.1080/01431160600972961. 
Ohde, T., H. Siegel, J. Reißmann, and M. Gerth. 2007a. "Identification and Investigation of Sulphur Plumes along the Namibian Coast Using the MERIS Sensor." Continental Shelf Research 27: 744-756. doi:10.1016/j.csr.2006.11.016.

Parsons, T. R., Y. Maita, and C. M. Lalli. 1984. A Manual of Chemical and Biological Methods for Seawater Analysis, 173. Oxford: Pergamon Press.

Perez-Torrado, F. J., J. C. Carracedo, A. Rodríguez-González, V. Soler, V. R. Troll, and S. Wiesmaier. 2012. "La Erupción Submarina De La Restinga En La Isla De El Hierro, Canarias: Octubre 2011-Marzo 2012.” Estudios Geológicos 68: 5-27. doi:10.3989/ egeol.40918.179.

Pingree, R. D., and C. Garcia-Soto. 2004. "Annual Westward Propagating Anomalies near $26^{\circ} \mathrm{N}$ and Eddy Generation South of the Canary Islands: Remote Sensing (Altimeter/SeaWIFS) and in Situ Measurement." Journal of the Marine Biological Association of the UK 84 (6): 1105-1115. doi:10.1017/S0025315404010549h.

Polovina, J. J., E. Howell, D. R. Kobayashi, and M. P. Seki. 2001. "The Transition Zone Chlorophyll Front, a Dynamic Global Feature Defining Migration and Forage Habitat for Marine Resources." Progress in Oceanography 49 (1-4): 469-483. doi:10.1016/S0079-6611 (01)00036-2.

Resing, J. A., K. H. Rubin, R. Embley, J. Lupton, E. Baker, R. Dziak, T. Baumberger, M. Lilley, J. Huber, T. M. Shank, D. Butterfield, D. Clague, N. Keller, S. Merle, N. J. Buck, P. Michael, A. Soule, D. Caress, S. Walker, R. Davis, J. Cowen, A.-L. Reysenbach, and H. Thomas. 2011. "Active Submarine Eruption of Boninite in the Northeastern Lau Basin." Nature Geoscience 4 (11): 799-806. doi:10.1038/ngeo1275.

Rivera, J., G. Lastras, M. Canals, J. Acosta, B. Arrese, N. Hermida, A. Micallef, O. Tello, and D. Amblas. 2013. "Construction of an Oceanic Island: In- Sights from the El Hierro (Canary Islands) 2011-2012 Submarine Volcanic Eruption.” Geology 41: 355-358. doi:10.1130/G33863.1.

Ruddick, K. G., F. Ovidio, and M. Rijkeboer. 2000. "Atmospheric Correction of Seawifs Imagery for Turbid Coastal and Inland Waters." Applied Optics 39 (6): 897-912. doi:10.1364/ AO.39.000897.

Sangrà, P., A. Pascual, Á. Rodríguez-Santana, F. Machín, E. Mason, J. C. McWilliams, J. L. Pelegrí, C. Dong, A. Rubio, J. Arístegui, Á. Marrero-Díaz, A. Hernández-Guerra, A. Martínez-Marrero, and M. Auladel. 2009. "The Canary Eddy Corridor: A Major Pathway for Long-Lived Eddies in the Subtropical North Atlantic." Deep Sea Research Part I: Oceanographic Research Papers 56: 2100-2114. doi:10.1016/j.dsr.2009.08.008.

Santana-Casiano, J. M., M. González-Dávila, E. Fraile-Nuez, D. De Armas, A. G. González, J. F. Domínguez-Yanes, and J. Escánez. 2013. "The Natural Ocean Acidification and Fertilization Event Caused by the Submarine Eruption of El Hierro." Scientific Reports 3 (1140): 1-14. doi:10.1038/srep01140.

Schmoker, C., J. Arístegui, and S. Hernández. 2012. "Planktonic Biomass Variability during a Late Winter Bloom in the Subtropical Waters off the Canary Islands." Journal of Marine Systems 95: 24-31. doi:10.1016/j.jmarsys.2012.01.008.

Shi, W., and M. Wang. 2010. "Characterization of Global Ocean Turbidity from Moderate Resolution Imaging Spectroradiometer Ocean Color Observations." Journal Of Geophysical Research 115: C11022. doi:10.1029/2010JC006160.

Shi, W., and M. Wang. 2011. "Satellite Observations of Environmental Changes from the Tonga Volcano Eruption in the Southern Tropical Pacific." International Journal of Remote Sensing 32 (20): 5785-5796. doi:10.1080/01431161.2010.507679.

Siebert, L., and T. Simkin. 2002. "Volcanoes of the World: an Illustrated Catalog of Holocene Volcanoes and Their Eruptions." Smithsonian Institution, Global Volcanism Program Digital Information Series, GVP-3. Accessed March 14. http://www.volcano.si.edu/world/

Siegel, H., T. Ohde, M. Gerth, G. Lavik, and T. Leipea. 2007. "Identification of Coccolithophore Blooms in the SE Atlantic Ocean off Namibia by Satellites and In-Situ Methods." Continental Shelf Research 27: 258-274. doi:10.1016/j.csr.2006.10.003.

Ssalto/Duacs User Handbook: (M)SLA and (M)ADT near-realtime and delayed time products. 2013. CLS-DOS-NT-06.034 Issue 3 rev 6. Nomenclature: SALP-MU-P-EA-21065-CLS. http://www.aviso.altimetry.fr/en/home.html

Stumpf, R. P., R. A. Arnone, J. R. W. Gould, P. M. Martinolich, and V. Ransibrahmanakul. 2003. "A Partially Coupled Ocean-Atmosphere Model for Retrieval of Water-Leaving Radiance from 
Seawifs in Coastal Waters." In NASA Technical Memorandum 2003-206892 SeaWiFS Postlaunch Technical Report Series, edited by S. B. Hooker and E. R. Firestone, Vol. 22, 51-59. Greenbelt, MD: NASA Goddard Space Flight Center.

Urai, M., and S. Machida. 2005. "Discolored Seawater Detection Using ASTER Reflectance Products: A Case Study of Satsuma-Iwojima, Japan." Remote Sensing of Environment 99: 95-104. doi:10.1016/j.rse.2005.04.028.

Wang, M., and W. Shi. 2007. "The NIR-SWIR Combined Atmospheric Correction Approach for MODIS Ocean Color Data Processing." Optics Express 15 (24): 15722-15733. doi:10.1364/ OE.15.015722.

Wang, M., S. Son, and L. W. Harding Jr. 2009b. "Retrieval of Diffuse Attenuation Coefficient in the Chesapeake Bay and Turbid Ocean Regions for Satellite Ocean Color Applications." Journal Of Geophysical Research 114: C10011. doi:10.1029/2009JC005286.

Wang, M., S. Son, and W. Shi. 2009a. "Evaluation of MODIS SWIR and NIR-SWIR Atmospheric Correction Algorithms Using Seabass Data." Remote Sensing of Environment 113: 635-644. doi:10.1016/j.rse.2008.11.005.

Weeks, S. J., B. Currie, A. Bakun, and K. R. Peard. 2004. "Hydrogen Sulphide Eruptions in the Atlantic Ocean off Southern Africa: Implications of a New View Based on Seawifs Satellite Imagery." Deep Sea Research Part I: Oceanographic Research Papers 51 (2): 153-172. doi:10.1016/j.dsr.2003.10.004.

Werdell, P. J., B. A. Franz, and S. W. Bailey. 2010. "Evaluation of Shortwave Infrared Atmospheric Correction for Ocean Color Remote Sensing of Chesapeake Bay." Remote Sensing of Environment 114: 2238-2247. doi:10.1016/j.rse.2010.04.027. 